This item was submitted to Loughborough's Research Repository by the author.

Items in Figshare are protected by copyright, with all rights reserved, unless otherwise indicated.

\title{
Seamount detection and isolation with a modified wavelet transform
}

PLEASE CITE THE PUBLISHED VERSION

http://dx.doi.org/10.1111/j.1365-2117.2008.00382.x

\section{PUBLISHER}

(c) The Authors Journal Compilation (c) Blackwell Publishing Ltd, European Association of Geoscientists \& Engineers and International Association of Sedimentologists

\section{VERSION}

AM (Accepted Manuscript)

LICENCE

CC BY-NC-ND 4.0

\section{REPOSITORY RECORD}

Hillier, John K.. 2019. "Seamount Detection and Isolation with a Modified Wavelet Transform". figshare. https://hdl.handle.net/2134/13038. 
This item was submitted to Loughborough's Institutional Repository (https://dspace.lboro.ac.uk/) by the author and is made available under the following Creative Commons Licence conditions.

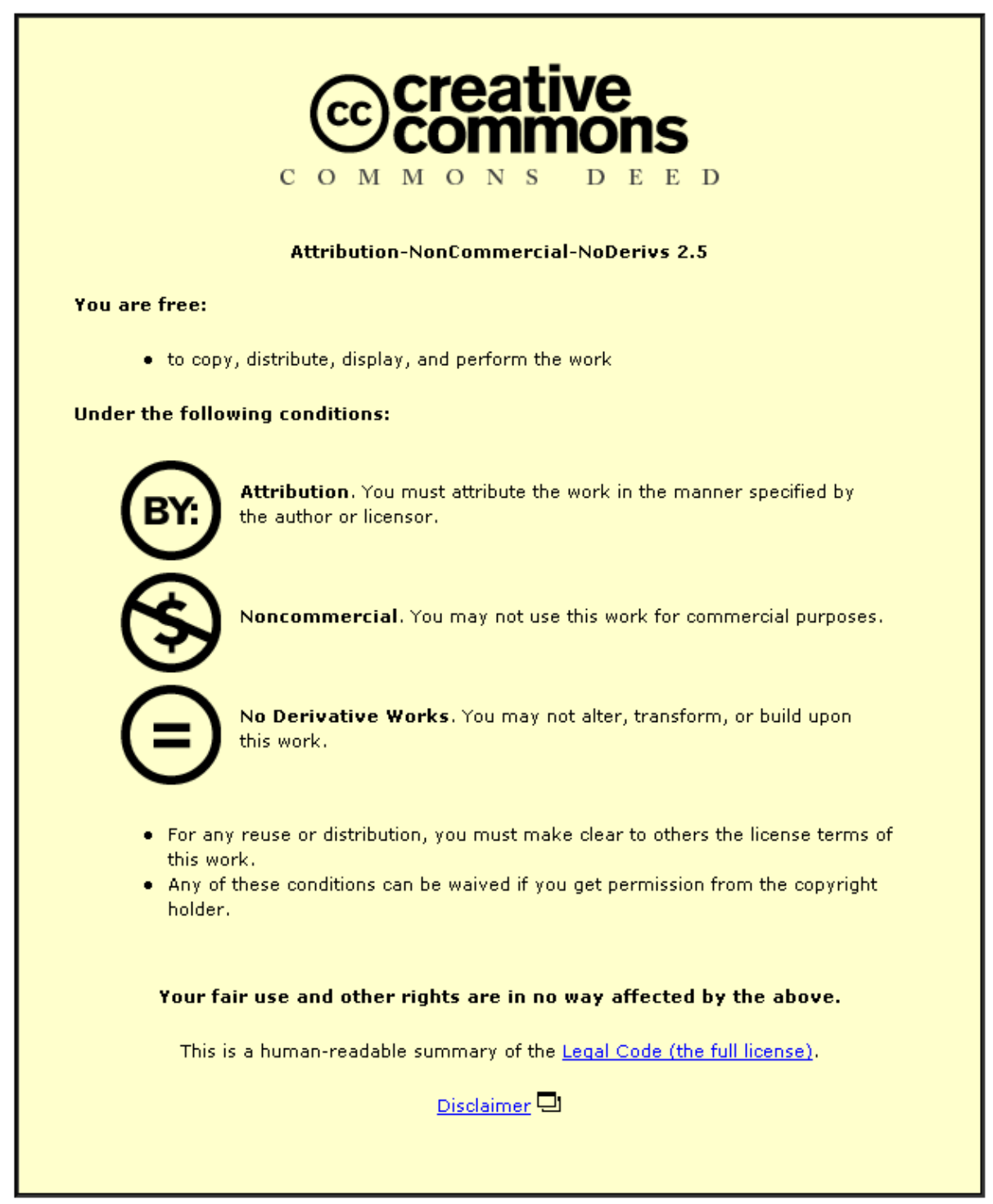

For the full text of this licence, please go to: http://creativecommons.org/licenses/by-nc-nd/2.5/ 


\title{
Seamount Detection and Isolation With a Modified Wavelet Transform
}

\author{
J. K. Hillier \\ Department of Earth Sciences, University of Cambridge, Downing Street, CB2 3EQ. Tel: 01223 \\ 764368 Fax: 01223333450
}

\begin{abstract}
The size, shape and number of seamounts, once detected and isolated from other features such as oceanic plateaus or trenches, have the potential to provide valuable constraints on important solid Earth processes, e.g. oceanic volcanism. The variability of seamount size and morphology, however, presents problems for computational approaches to seamount isolation. This paper develops a novel and efficient wavelet-based seamount detection routine 'SWT'; the first use of multiple scales of analysis to directly isolate edifices from bathymetric data. Only weak shaperelated criteria are used and no a priori knowledge of the scale and location of the seamounts is required. For a bathymetric profile collected on cruise v3312 SWT matches, to within $25 \%$, the dimensions of five times the number of the features determined by manual inspection than does the best statistically-based (e.g. mean, median or mode) sliding window filter. The size-frequency distribution, a key descriptor of seamount populations, is also much better estimated by the SWT method. As such, the SWT represents a step towards the goal of objective and robust quantification and classification of seamounts.
\end{abstract}

\section{Introduction}

Seamounts are, by their traditional definition [e.g. Menard, 1959], submarine mountains that stand > $1 \mathrm{~km}$ above the surrounding seafloor, although the term is now commonly applied to much smaller features [e.g. Jordan et al, 1983; Hillier \& Watts, 2007]. More specific nomenclature (e.g. knoll, hill, guyot, island) is also sometimes used to distinguish sub-categories of feature, although not necessarily in any standardised way. Allain et al [2008] detail this nomenclature in their compilation of seamount databases. This paper is concerned with detecting seafloor features so that their shape may be assessed and, if desired, later sub-categorised. So, for the purposes of this paper, 'seamount' will be used as an umbrella term denoting features up to $\sim 200 \mathrm{~km}$ in width (the scale of 'Big Island' Hawaii) that rise above the surrounding seafloor in an oceanic setting.

The term 'seamount' does not imply any particular mode of origin, but if an origin can be inferred these features constitute a valuable set of observational constraints on fundamental solid Earth processes. For example, by analogy with oceanic islands such as Hawaii and from samples of igneous rock [e.g. Koppers et al, 2003; Clouard \& Bonneville, 2005] larger seamounts, at least, are almost certainly volcanic edifices [e.g. Menard, 1959; Wessel, 2001; Hillier, 2007]. As such the size, number, and distribution of seamounts can be argued to reflect the generation and ascent of magma; processes dictated by properties of the lithosphere and fluid mantle below. For example, seamount height, $h$, has been linked to magma-chamber depth varying with lithospheric age [Vogt, 1974; Epp, 1984]. Alternatively, $h$ may be limited by flexural stresses in the lithosphere [Wessel, 2001]. It is therefore desirable to accurately, reproducibly and objectively locate and quantify the morphology of seamounts.

\subsection{Isolating seamounts}

In order to quantify the size and shape of a seamount, it is first necessary to distinguish the seamount, for example from nearby seamounts. It must also be distinguished from other bathymetric signals in the area such as larger features (e.g. hot-spot swells) or indeed a flat-lying 
surface in the same area upon which it is superimposed. Once distinguished, a viable estimation of the seafloor depth that would exist had the seamount not been created must be made. Viewed on a depth-distance profile across the feature this estimation will run beneath the seafloor expression of the feature. The term 'isolating' is adopted for this process. The 'correct' outcome of such seamount isolation is not necessarily obvious: for instance, consider a volcano with a pelagic apron that merges into the abyssal plain. Various automated methods for isolating seamounts have been proposed although never compared to each other in terms of their ability to accurately isolate populations containing many differently sized seamounts. In order to evaluate methods, the following criteria are proposed.

1. Be exactly reproducible between studies.

2. Inside seamounts, define the base of the seamount by a geologically reasonable estimate of water depth had the seamount not existed.

3. Outside seamounts, exactly reproduce the measured seafloor depths - not doing so may create artefacts that might be misinterpreted as seamounts.

4. Should reliably isolate seamounts in the presence of other features such as hot-spot swells and trenches (e.g. Marianas).

5. Be equally effective for all size-scales of feature, however size is defined (e.g. height or width). Preferably no lower detection limit on size detection or coefficient threshold should be used.

6. Handle a size-based hierarchy of features (e.g. a cone on a volcano on a hot-spot swell). Specifically, retain information on the hierarchy but provide a method to select the most significant or pertinent features from the hierarchy.

7. Be objective.

8. Identify seamounts using the fewest possible a priori assumptions about their shape.

9. Should work with no a priori knowledge of where a seamount is or how big it is, e.g. without specifically delimiting an area of seafloor to be assessed by the methodology.

10. Use measured data without further re-sampling it (e.g. by using $2^{n}$ points along a profile) ship-track bathymetry data are commonly unequally spaced.

11. If the technique is '2D' (i.e. $x$ vs. $z$ profile), it should ideally be extendable into '3D' (i.e. surfaces with $x, y, z$ data).

Visually, it is possible to recognise seamounts from profiles [e.g. Menard, 1959; Jordan et al, 1983; Smith \& Jordan, 1988; Smith, 1988], contoured bathymetric charts [e.g. Batiza, 1982; Marova, 2000], or multi-beam swath bathymetry [e.g. Abers \& Parsons, 1988; Smith \& Jordan, 1988; Scheirer \& Macdonald, 1995]. This manual interpretation of bathymetry can account for many of the proposed criteria and obviously requires the least computer coding, so has remained in common use. If the criteria for defining a seamount are explicitly stated [e.g. Smith \& Cann, 1992], the results have the potential to be closely reproducible. Despite this, with an estimated 40,000 seamounts $(h>1 \mathrm{~km})$ [Hillier \& Watts, 2007] exist recorded in $40 \times 10^{6} \mathrm{~km}$ of single-beam echosounder profiles collected on $\sim 6,000$ publicly available research cruises. So, automated techniques are desirable.

Numerous computer-based procedures have been proposed that aim to isolate seamounts. Many of these determine a larger-scale 'regional' bathymetry that is then subtracted from the observed bathymetry to leave a 'residual' bathymetry as an estimate of the seamounts. However, the 'key issue in all [such] filter based separation techniques is the choice of filter width' [Wessel, 1998]. Namely, at which width-scale is the regional bathymetry defined? Too small and the regional becomes shallow inside large seamounts, whilst too large and the regional cuts through seamounts standing in a depression. Progress has being made on automated width selection for a single feature [Wessel, 1998] and reducing artefacts for seamounts on slopes [Kim \& Wessel, 2008], but have not 
yet been perfected and regional based techniques will always struggle where 'normal' unperturbed seafloor upon which to base the regional is rare [Hillier \& Watts, 2004, 2005].

An alternative approach is to identify the seamounts directly. Identifying seamounts by their own descriptive characteristics, as opposed to being different from their surroundings, certainly has appealing features. Direct detection, however, must create a categorisation that eliminates both false positives and negatives. Thus, collating a complete set is not trivial and considering all the alternatives is computationally expensive. Both existing methods to directly isolate seamounts of multiple scales from bathymetry data [Behn et al, 2004, Hillier \& Watts, 2004] have limitations. So, a significant remaining challenge is to simultaneously and accurately isolate multi-scale seamounts whatever their shape with no a priori knowledge of where the seamounts are or how big they are. Wavelet analysis provides information localized in both position and scale and thus offers a way of accessing the multi-scale problem.

This paper presents a routine that combines numerical approaches not previously applied to seamount isolation with the modification of an existing idea [Wessel, 1998] in order to build towards the goal of objective and robust quantification and classification of seamounts. The approach taken in the routine is based on wavelet analysis, and has several key similarities, but is less mathematically involved and more strongly routed in the space domain than some treatments. So, it is dubbed Spatial Wavelet Transform 'SWT'. Firstly, existing methods that may be applied to the task of seamount isolation are reviewed, wavelet analysis introduced, then the SWT method described and assessed.

There are other issues critical in the quantification and geological interpretation of seamounts including: Is a seamount a volcano? How is it best to account for incomplete data coverage [Jordan, 1983; Hillier \& Watts, 2007]? These, however, are beyond the scope of this paper.

\section{Existing Seamount Isolation Techniques}

Computational techniques designed to isolate seamounts operate in two ways. Either they compute a larger-scale 'regional' [e.g. Wessel, 1998] bathymetry at a selected scale that aims to include undulations such as 'hot-spot' swells and oceanic plateaus, yet passes beneath seamounts. Subtracting this regional trend from the original bathymetry isolates seamounts in a 'residual' component of bathymetry. Alternatively, seamounts may be detected directly. Both approaches are complicated because seamounts vary dramatically in size (anything $<200 \mathrm{~km}$ in width) and shape [e.g. Jordan et al 1983; Smith, 1996].

\subsection{Computing 'regional' bathymetry}

The earliest computed regional bathymetries were means (either un-weighted or weighted with coefficients to form a Gaussian filter) within an area [e.g. Watts, 1976; McKenzie, 1980; Cazenave, 1986; Sandwell \& Renkin, 1988], or long wavelengths from a Fourier transform [e.g. Watts \& Daly, 1981]. Long wavelengths across a region may also be selected using a wavelet transform [Mofjeld et al, 2001, 2004]. However, seamounts are constructs (i.e. only point up, never down). In the vicinity of seamounts this causes regional depths estimated by these methods to be shallower than the surrounding seafloor they aim to represent [Watts et al, 1985; Smith, 1990; Cserepes, 2000]. This is because the methods do not remove or ignore any of the height of a seamount; rather they simply spread it out. Seamount heights, defined as summit height above the regional, are therefore underestimated (see Figure 8 in Section 5.2).

In response to this bias caused by seamounts statistical measures robust to outliers (i.e. median and mode) were therefore utilized [e.g. McNutt \& Fischer 1987; Smith, 1990; McNutt \& Sichoix, 1996; 
Levitt \& Sandwell, 1996; Sichoix, 1998]. These significantly mitigate this problem, but still have some tendency to pass through, rather than beneath, seamounts where many seamounts co-exist [Hillier \& Watts, 2004] or occur down trenches (Figure 12). A further improvement applicable to gridded data only uses directional filtering to improve the regional-residual separation for medians where the seafloor is sloping [Kim \& Wessel, 2008]. Overall, these techniques perform well when the filter width (i.e. radius of the circle in which computations are conducted) is correctly optimized to match the width-scale of the seamount. Choice of filter width in each circumstance is therefore key [Wessel, 1998].

In order to choose a 'correct' filter width, some quantitative criterion is needed. For conventional spectral techniques a Wiener-filter technique [e.g. Gupta \& Ramani, 1980] can be used, which utilises a distinction between power spectra of the regional and residual components. For topographic data, however, spectral overlap is commonly too severe to meaningfully determine any 'ideal' Wiener filter. In addition, robust filters such as the median do not predictably affect the power spectra of the regional and residual, so a decision must be based on properties measurable in the space domain [Wessel, 1998].

For Optimal Robust Separation (ORS) of regional and residual Wessel [1998] selects the width of spatial median filter that maximizes the mean amplitude of the residual height $\bar{h}$ defined as

$$
\bar{h}=\frac{V}{A}
$$

where $V$ is volume and $A$ is area inside a selected contour (e.g. $50 \mathrm{~m}$ ). This ORS technique provides a clear lower limit on the optimal filter width but less constraint on the upper limit [Wessel, 1998; Minshull \& Charvis, 2001; Ali, 2003] and, for the Marquesas Islands at least, the optimal width is significantly changed by 'small changes due to choice of area included in the analysis' [Minshull \& Charvis, 2001]. A fairly broad maximum still remains with the refinements of Kim \& Wessel [2008]. Thus, despite proving an objective procedure, the area for analysis that must be specified $a$ priori for each set of volcanoes and a substantial subjective factor remains. Outside geology, median filters that adapt their width along a time series according to criteria in the fractal dimension [Cheng et al, 2001] and other 'adaptive', 'parallel', or 'multi-channel' have been implemented [e.g. Yatawara, 1991; Lin, 2000], but as yet a fully automated and objective regional-residual method based on computation of a regional and capable of isolating seamounts of different sizes across the oceans has yet to be developed.

\subsection{Direct detection}

In contrast to examining seamounts in the product of a regional-residual division, some procedures aim to identify seamounts directly. Since seamounts vary dramatically in size (anything $<200 \mathrm{~km}$ in width) and shape [Jordan et al 1983; Smith, 1996] the direct detection of many seamounts is more complicated than approximating a regional bathymetry. Detection routines must either integrate information from multiple scales, be scale-invariant, or find some loophole.

Since 'moderate variations in seamount shape do not affect the [geoid] signature significantly' [White et al, 1983] the shape required for pattern-matching techniques is less critical than for bathymetry, and so direct detection routines in altimetry data have exploited this approach. Lazarewicz \& Schwank [1982] used a 'matched filter' algorithm of White et al [1983] to detect the location of seamounts in SEASAT altimeter profiles. In essence, seamounts of a single width were sought out across a profile as events statistically distinct from the measurement noise in the profile, but to permit calculation in the frequency domain several approximations (e.g. approximating the geoid signature of a conical seamount as a periodic function) were needed. Re-sampling of data to 
$2^{\mathrm{n}}$ evenly spaced points along the profile and a detection threshold were also necessary. Detection capability for seamounts as small as $1 \mathrm{~km}$ [White et al, 1983] with 'detection effective across a wide range of [shape] parameters' [Lazarewicz and Schwank, 1982] was claimed. Craig \& Sandwell [1988], however, found identification of signals corresponding to seamounts by-eye more reliable. Furthermore, whilst White et al [1983] note that their pattern matching technique could be done with a range of scales, this was never implemented.

Wessel and Lyons [1997] next attempted an algorithm for seamount detection in altimeter data, but this time for gridded vertical gravity gradients (VGG). Their routine first identified local maxima (i.e. points having a greater amplitude than those all around them), then required these points to exhibit a monotonically decreasing trend in both $\mathrm{x}$ and $\mathrm{y}$ directions for $\sim 11 \mathrm{~km}$ and have an amplitude $>30$ Eötvös. Where appropriate, multiple neighbouring peaks were amalgamated according to amplitude and separation, and then seamount dimensions were estimated through forward modelling. The methodology neatly achieves invariance to the width-scale of seamounts, but cannot be easily transferred from smooth altimetry data to rough bathymetry: smoothing related to the width-scale of the seamount would be necessary, but these width-scales are unknown at the time of detection. So, neither routine described so far is proven for the analysis of bathymetry data nor are they designed to isolate seamounts as defined above.

The only existing methods to directly isolate seamounts of multiple sizes from bathymetry data are the automation by Behn et al, [2004] of the 'closed contour' method of Smith and Cann [1992] and the MiMIC algorithm [Hillier \& Watts, 2004] which seeks to replicate the act of manual or graphical regional-residual separation. Both are methods that are invariant to scale rather than analyses at multiple scales.

The closed contour method has been used on swath bathymetry to more rigorously apply previous definitions of a seamount [e.g. Batiza, 1982]. The definition in both Smith \& Cann [1992] and Behn et al [2004] is that seamounts have a relief of $>50 \mathrm{~m}$ on all sides and have approximately equant plan shapes (aspect ratio $\alpha$ of $<2$ ). Qualitatively [Smith \& Cann, 1992] the contour was started at the shallowest point of the break of slope at the seamount's base (often the saddle between 2 features) and continued until the seamount was circumscribed. Behn et al [2004] automated this process, but scant details are given. Presumably, all closed contours were identified then all surrounded by a deeper contour, or without a data point $>50 \mathrm{~m}$ shallower within, or with $\alpha>2$ were discarded. This routine is width-scale invariant, but has problems when seamounts are to some extent joined. With the method of Smith \& Cann [1992] height and size were underestimated. For Behn et al [2004] nearby subsidiary features significantly stretched the ellipse fitted to the basal contour (see their Fig 2.), perhaps with undue influence. In certain circumstances such as island chains (e.g. Hawaii) problems with joined features would become severe. For both methods, a sloping seafloor caused heights to be underestimated [Behn et al, 2004].

Concurrently Hillier \& Watts [2004] developed a scale-invariant algorithm, MiMIC, targeted at ship-track bathymetry data. Moving along a profile this routine identifies every shallow section of bathymetry that could be a seamount, tests it according to morphological criteria, then moves incrementally if the tests are unsuccessful but jumps and draws a line underneath seamounts. During internal computations all sections of bathymetric profile are scaled to have widths and heights of one unit, so it is truly independent of scale. MiMIC successfully isolates seamounts from 0.1 to $6 \mathrm{~km}$ tall in the presence of larger-scale features (e.g. trenches, hot-spot swells), however, it too uses a flat line underneath seamounts. Moreover, to analyse gridded data a mesh of profiles must be used and it is difficult to see how MiMIC could be extended to function intrinsically on a grid. 
Wavelets have been used like a Fourier transform to remove short wavelength bathymetry $(\lambda<100$ $\mathrm{km}$ removed tapered to leave $\lambda>400 \mathrm{~km}$ unaffected) [Mofjeld et al, 2001, 2004]. Their power to vary filter scale with location has not, however, been used as yet in seamount isolation. Such techniques have been developed for analogous problems. Identifying stars in an image of a cloudless night sky is such a problem: imagine light intensity as depth with bright stars equating to shallow depths. Stars have varying size and intensity, may overlap, or may be found inside larger bright objects such as galaxies. Geologically the larger objects might be oceanic plateaus or hot spot swells. A 'Multiscale Vision Model', based on a wavelet transform, has been developed for this stellar problem [Starck \& Bijaoui, 1994; Starck et al, 2000].

\section{Wavelet Analysis}

Wavelets are mathematical tools that are commonly applied to time series i.e., any sequence of observations associated with an ordered independent variable. In this case a sequence of heights $\left(z_{i}\right)$ associated with distances $\left(x_{i}\right)$ monotonically increasing along a profile, where $i=0,1, \ldots \ldots N-1$ and $N$ denotes the number of values in the time series. A wavelet (Figure 1), as the name suggests, is a 'small wave.' This small wave grows and then decays over a limited period, in this case a limited range of distances along the profile. In contrast a sine function would keep oscillating along the entire time series.

Analysis with wavelets tells us how weighted averages of other functions (e.g. a bathymetry profile) vary from one averaging location to the next. The width of the wavelet defines a scale $(\lambda)$, and the position of its centre a location $(x)$. By varying $x$ and $\lambda$ a picture is built up of how the averages vary with scale and location, a product known as a 'wavelet transform' (WT). WTs are twodimensional functions of $x$ and $\lambda$ derived from a one-dimensional signal, and have 'WT coefficients' $\left(C_{x, n}\right)$ representing the magnitude of the variations.

The Haar wavelet (Figure 1a) essentially looks at differences in averages that are analogous to the sample mean across its width: specifically, the difference between averages in the intervals $x>x_{i}>$ $x-\lambda$ and $x+\lambda>x_{i}>x$. The Mexican hat wavelet (Figure 1b) [e.g. Gaillot et al, 1997] yields the difference between a weighted average in the centre and an average of two weighted averages surrounding it. For a bathymetric profile, coefficients for such a wavelet will be maximized when it is centred on an area shallower than its surroundings, namely a seamount. Furthermore, when the width of the wavelet is appropriate to the seamount's width, coefficients will be largest. Thus, wavelet analysis has the potential to provide information on how big seamounts are and where they are without any a priori stipulations about the shape of the seamount.

Much of this section is a condensation of Chapter 1 of Percival \& Walden [2000], so the reader is referred there for a fuller introduction to wavelet analysis.

\section{The 'SWT' Method of Seamount Isolation}

The proposed 'SWT' method of isolating seamounts consists of 3 stages.

1. Wavelet analysis is used to create a wavelet transform (WT) of a bathymetric profile.

2. From the WT the approximate width and location of seamounts are determined.

3. Using the derived width and location in conjunction with the original bathymetry the limits of the seamounts (i.e. the edges of their extent in space) are determined. 
The three stages are detailed below starting with their general principles. The exact methods chosen are justified and, where necessary, refinements for this particular application are explained.

\subsection{Wavelet Analysis}

The wavelet chosen for this implementation is shown in Figure 2. Here, its width $w$ is defined as the whole range where it has non-zero amplitude, and its location is centred on a data point $x_{i}$. The amplitude of the wavelet transform is a weighting $\left(W_{i}\right)$ used in computing the average of another function, in this case heights along a bathymetric profile. Heights $\left(z_{i}\right.$ - positive up) are associated with distances $\left(x_{i}\right)$ along the profile, where $i=0,1, \ldots \ldots N-1$ and $N$ denotes the number of values in the time series. Coefficients $\left(C_{x, w}\right)$ of a WT can then be computed for evenly spaced (i.e. $x_{i+1}-x_{i}$ is constant) data as

$$
C_{x, w}=\frac{\sum_{i=j}^{i=k} z_{i} \cdot W_{i}}{\sum_{i=j}^{i=k}\left|W_{i}\right|}
$$

where $j$ is the first data point for which $x>x_{i}-(w / 2)$ and $x<x_{i}+(w / 2)$, and $k$ is the last. This is linearly proportional to the difference between an average in the centre and the average of two weighted averages surrounding it: note the similarity to the Mexican Hat wavelet in Section 3. If the mean height for the left section is $z_{l}, z_{r}$ for the right hand section, and $z_{c}$ for the central part, the differences between the averages for the centre and outsides are $\left(z_{c}-z_{r}\right)$ and $\left(z_{c}-z_{l}\right)$ respectively making the average difference between centre and edges $\left(2 z_{c}-z_{r}-z_{l}\right) / 2$. For evenly spaced data $C_{x, w}$ as defined above is $0.25^{*}\left(2 z_{c}-z_{r}-z_{l}\right)$. For unevenly spaced data, experience indicates that it is more stable to calculate $C_{x, w}$ from the mean heights $z_{l}, z_{r}$ and $z_{c}$. So, since bathymetry data is commonly unevenly spaced, this is how this SWT method calculates $C_{x, w}$. Where no data exists in one of the sections 'NaN' ('not a number' i.e. no data) is the value assigned to $C_{x, w}$. In order to create a WT $C_{x, w}$ is computed at locations $x_{i}$ for $0<i<N-1$ at a scale $w$, a procedure repeated for sufficient scales $w$ that the complete (continuous) WT is well sampled.

In practice, for ship-track bathymetry data, the following steps between scales $(\Delta w)$ have been found to be sufficient; $\Delta w=0.1 \mathrm{~km}$ for $0.1<w<=1, \Delta w=1 \mathrm{~km}$ for $1<w<=25, \Delta w=5 \mathrm{~km}$ for 25 $<w<=100$, and $\Delta w=10 \mathrm{~km}$ for scales greater than this.

Figure $3 \mathrm{~b}$ shows an approximation of the complete WT, computed as described above, for a synthetic profile across the summit of a single conical seamount centred on $x=0.0 \mathrm{~km}$ surrounded by a flat-lying seafloor (see Figure 3a). The WT, a 2D plot of $C_{x, w}$ derived from the profile, has scale of the wavelets on the $y$ axis and location of the wavelets on the $\mathrm{x}$ axis with the WT function's values plotted according to a grey scale. The largest coefficients (light shades) at each $w$ are directly above the peak of the seamount. The largest overall coefficient is at $w=9.0 \mathrm{~km}$ and is plotted as a white circle. This maximum can be thought of as indicative of the wavelet that 'best fits' the seamount. Figure $3 \mathrm{a}$ also plots this circle, displayed at its correct position on the $\mathrm{x}$ axis with the width of the largest coefficient $C_{0,9}$ shown as a thin line $( \pm w / 2)$ and the span of this wavelet's central section in bold $( \pm w / 4)$. Note that where the seafloor is flat coefficients are zero.

To further illustrate the behaviour of WTs of height profiles Figure 4 shows a profile across a seamount of identical size to that in Figure 3, and a smaller seamount at $x=8.0 \mathrm{~km}$, on a sloping seafloor. Coefficients on the planar but sloping seafloor are zero. Best-fitting coefficients are again plotted as white circles, which in terms of $(x, w)$ are located at $(0.7,6.0)$ and $(8.2,2.0)$. These best- 
fitting wavelets are up-slope of the seamounts' centres. Also note that the coefficients for the smaller seamount are smaller. The best-fitting values of scale and location of the seamounts demonstrate why these WT based results are only estimates, which must be later used to accurately determine the limits of seamounts (Section 4.3). It is possible, however, that the smaller seamount could occur somewhere on top of the larger one, and thus the significant feature in each location must be chosen before the limits can be determined (Section 4.2).

Before continuing it is worth noting refinements to the computation of $C_{x, w}$. These refinements are possible because of the wavelet and computation method chosen and are made in order to repress aspects of the WT not of interest to seamount detection whilst retaining those that are. Trenches, for instance, are not of interest but cause large coefficients because either $z_{l}$ or $z_{r}$ can be much deeper than $z_{c}$. This is the case for the Marianas Trench as encountered on cruise v3312 and the dominant vertical white strips in the WT of Figure 5a are caused by this effect. Thus, refinement 1 for the SWT method is that if either edge of the wavelet contains heights whose average is above that in the centre (i.e., $z_{l}$ or $z_{r}>z_{c}$ ) $C_{x, w}$, is set to zero. Figure $5 \mathrm{~b}$ shows how this suppresses the artefacts at the edge of the trench. Signals more cleanly related to seamounts are also produced, an effect particularly evident for the small seamounts to the left of Figure 9c. The trench edge features, however, still dominate in amplitude. So, to prevent large coefficients (white) at the edge of a large trench, refinement 2 is introduced so that the lowest of $z_{r}$ and $z_{l}$ is set to the value of the higher one before $C_{x, w}$ is computed i.e., in essence one side is not allowed to fall down the trench to produce the large coefficients. Figure 5c demonstrates the effect of this last refinement. Large coefficients (white) now represent the large seamount at $\sim 1900 \mathrm{~km}$, and the broad low-amplitude bulge (grey shaded) before the trench has small coefficients allowing it to be suppressed according by its shape and an improved determination of seamount sizes and locations achieved (Sections 4.2 $\& 4.3$ ). It is also convenient to set all $C_{x, w}<0$ to 0 , although this is done purely to tidy up $C_{x, w}$ and does not affect later processing.

\subsection{Determining Location and Width of Seamounts From the WT}

The coefficients best representing seamounts can now be selected from the two dimensional array of $C_{x, w}$ forming the WT of the bathymetric profile. For each individual feature higher values of $C_{x, w}$ indicate a better fit in terms of scale and location, so $w$ and $x_{i}$ associated with the highest coefficients may be taken as an initial estimate of the scale and location of a seamount (e.g. Figure 2). However, the seafloor contains a multi-scale hierarchy of features: cone on a seamount, itself on a hotspot swell, itself on a superswell, and so on [e.g. Hillier \& Watts, 2004]. The WT contains information about all of these. A procedure in needed to both select the best fitting coefficient for each seamount, but also to select seamounts over subsidiary cones and broader flatter features such as flexural bulges.

The WT consists of a list of coefficients $C_{x, w}$. Each $C_{x, w}$ is associated with a width $w$, an amplitude $A$, and a measure of how steep-sided the feature is $(S=A / w)$. In general, when going through the list, a smaller $C_{x, w}$ within the central range $( \pm w / 4)$ of a larger amplitude $C_{x, w}$ is eliminated. The exception is that smaller amplitude features can eliminate larger ones if they are both relatively steeper sided $\left(\mathrm{Sr}=\mathrm{S}_{\text {small }} / S_{\text {large }}>3.0\right)$ and the coefficients are not too much smaller $\left(\mathrm{Cr}=C_{\text {large }} /\right.$ $C_{\text {small }}<4.0$ ). The values of the 'steepness ratio' $S r$ and 'coefficient ratio' $C r$ are user defined constants that have be found to usefully discriminate between the flexural bulges and seamounts e.g. on the flanks of Hawaii (see Figures 8 \& 9 -Section 5.2).

To implement this procedure, each $C_{x, w}$ from the list is taken in turn and these steps applied

1. Could this coefficient $C_{x, w}$ best represent a seamount? Compare $C_{x, w}$ to each other coefficient within the central part of the wavelet that generated $C_{x, w}$ i.e. $x_{i} \pm w / 4$. If any other 
coefficient within this range is larger the answer is 'no' unless $C_{x, w}$ is more than a quarter of the size of the other and over 3 times steeper sided.

2. If no, eliminate $C_{x, w}$ (i.e. delete from list).

3. If yes, eliminate all other coefficients within $\pm w / 4$.

The method can be thought of as scanning coefficients for all scales $w$ and eliminating them as appropriate. After all coefficients in the list have been assessed, only those coefficients that best fit seamounts remain. This method is invariant to the order of coefficients in the list. Best fitting coefficients are the white circles (e.g. Figures 3,4,5). The best-fitting coefficients are estimates of the size and location of all the seamounts within a profile. This information can then be used to estimate the precise limits and dimensions of the seamounts in a context where the size and location of each seamount and those surrounding it are known.

\subsection{Delimiting and Isolating Seamounts}

From the WT the location and size of the seamounts are estimated as $x_{i}$ and $\pm w / 4$ (central portion of the wavelet - Figure 2) of the wavelet best-fitting the seamount (Section 4.2). With the wavelet chosen for this SWT method it might be expected that $\pm w / 4$ would exactly equate to the true width of that seamount. As illustrated with conical seamounts in Figures 3 and 4 , however, $\pm w / 4$ invariably underestimates the true width of a seamount. So, for each seamount located in the WT, ranges $\pm w / 4$ should be extended to estimate the true dimensions. How, and by which criteria?

The main criterion is adapted from the ORS method of Wessel [1998], but its implementation is by necessity markedly different. Wessel [1998] uses the ratio of enclosed volume to plan view area (see Section 2.1). On a profile, the SWT method quantifies a cross-section of a seamount and uses a ratio, $r$, of the length of the outline, $o$, to the area of the seamount $A$. The baseline underneath the seamount is a linear interpolation between the limits $\left(x_{l} \& x_{r}\right)$ of the seamount, and $r$ is

$$
r=\frac{A}{O}
$$

Figure 6 illustrates the various quantities. The ORS method [Wessel, 1998] tries an array of width scales for a sliding window filter to find the best regional-residual separation, whereas in the SWT method the limits of seamount are extended outward in order to maximize $r$. Why $r$ is maximized and how the right hand and left hand limits are, in turn, stepped outward are expanded upon below.

In general, for synthetic seamounts at least (e.g. Figures $3 \& 4$ ), and most real bathymetries, $r$ tends to increase as a seamount's range is increased up to its true size, whereupon it reduces. $r$ increases within a seamount as $r$ increases for larger congruent objects: compare $r$ for a square with 1 unit side to that of a 2 unit side. If either limit becomes shallower as it moves outside the seamount $A$ will decrease and so will $r . \quad r$ is a comparison of 2 summations and so, in a similar way to integration, is intrinsically relatively stable to noise in the depth data. Computationally, however, when moving either limit outwards from a seamount's summit $\left(x_{s}\right)$ a range of $x$ values proportional to the size of the seamount must be considered so that subsidiary topographic highs can be moved over. Also, in a minority of circumstances $r$ is not self-limiting when a seamounts true size is reached, so two geometrical restrictions are necessary: 1) Gradient at the edge of a seamount is not permitted to drop below $1 / 5^{\text {th }}$ of that in the central portion, which helps prevent excursions by the limits onto abyssal plains 2) Neither limit can become $>25 \%$ deeper than the other (summit used as datum), which prevents the limits descending trenches. These increase the stability of the SWT interpretation. The computational sequence is detailed below. 
1. Order the seamounts identified from the WT by magnitude of their $C_{x, w}$.

2. Start with the seamount of largest $C_{x, w}$.

3. Redefine seamount location and width: From the WT the seamount's width and location are $\pm w / 4$ and $x_{i}$ respectively. Redefine the location as the location of the summit $\left(x_{s}\right)$ i.e. the highest point within $x_{i} \pm w / 4$. Summit height is $z_{s}$. Redefine width of the seamount as $x_{r}-x_{l}$ where $x_{r}$ and $x_{l}$ are the largest and smallest distances along profile within $x_{i} \pm w / 4$.

4. Define gradient at centre of seamount, $G$, as the average magnitude of the gradient between summit and edges i.e. $\left(z_{l}-z_{s}\right) /\left(x_{l}-x_{s}\right)$ and $\left(z_{s}-z_{r}\right) /\left(x_{s}-x_{r}\right)$.

5. Expand the limits by 1 step (may be of several data points).

a. The limits will be allowed to expand at most by $25 \%$ of the width of the seamount, $0.25\left(x_{r}-x_{l}\right)$. Compute this. $25 \%$ is a user-defined coefficient $W f$.

b. Move right hand limit of the seamount $x_{r}$ outwards (i.e. away from $x_{s}$ ) if this increases $r$.

i. Compute $r$ for seamount with limit at $x_{r+1}$ (i.e. outward step of one data point).

ii. Compute gradient ( $g$ ) for the outer portion of seamount, then check that $G / g$ $<G r$ where $G r=5.0$. $G r$ is a user-defined constant. The outer portion is defined as the $25 \%$ furthest from the summit in a distance range $x_{s}$ to $x_{r+1} . g$ is gradient between points at the 2 extremities of this outer portion. The $25 \%$ fraction for the 'outer portion' is a user defined constant $O p=0.25$.

iii. Check that the depths of the limits are within $25 \%$ of each other using the seamount's summit as a datum i.e. $z_{s}-z_{r+1}<1.25\left(z_{s}-z_{l}\right)$. The $25 \%$ is a userdefined coefficient $\mathrm{Hr}$ or 'height ratio'.

iv. Check that the limit proposed does not encroach inside the already computed limits of any larger seamount.

v. If $r$ has increased and the 3 conditions (gradient, edge-depth, nonencroachment) are fulfilled, note new $x_{r}$, leave loop, and go to step 5c

vi. Repeat incrementing limit outwards (i.e. step 5b) whilst it is within the $25 \%$ restriction set in step 5a. If $r$ cannot be increased within this restriction, do not alter $x_{r}$ from its value at the beginning of this step (5b).

c. Do equivalent for left hand limit $x_{l}$.

d. If neither steps $5 \mathrm{a}$ nor $5 \mathrm{~b}$ allow the limits to be moved, try moving both limits out by 1 data point.

6. Repeat step 5 until no further movement is possible.

7. Remove any smaller seamounts within the established limits of this seamount

8. Repeat (i.e. go to step 3) for the seamount with next largest remaining $C_{x, w}$ from the WT derived list.

To account for very irregular bathymetry data the code accounts for inconsistencies and exceptions e.g. resulting from a large data gap next to a seamount. Alternatively, data could be re-sampled to make horizontal and vertical spacing between consecutive points small with respect to the seamounts.

After the analysis above (parameters collated in Table 1), the limits of all the seamounts are precisely known. Thus, their height, width, location are known and it is simple to parameterise them, for example as flat-topped cones [e.g. Jordan et al, 1983]. Hillier [2007] details an efficient numerical method for approximating seamounts as flat topped cones. A regional bathymetry is calculated by retaining the original measured bathymetry outside seamounts, whilst inside seamounts using a linear interpolation between the limits of the seamounts. 
The SWT method has been tested on a variety of datasets spanning the Pacific Ocean. The four cases below illustrate the performance of the method both in how well it produces visually acceptable interpretations and in its effect on the size and number of seamounts detected on profiles. Robustness to the value of user-defined constants is also demonstrated.

\subsection{Synthetic Seamounts}

Following Kim \& Wessel [2008] the synthetic of a conical seamount with a radius of $3 \mathrm{~km}$ and summit height of $3 \mathrm{~km}$ above a planar but tilted surrounding seafloor is examined. The planar seafloor is the correct regional depth. This configuration poses difficulties for regional-residual separation techniques that compute the regional directly e.g. a median filter [Wessel, 1998]. The directional median filtering developed by Kim \& Wessel [2008] overcomes this, but it is still a good test for the SWT technique.

Figure $7 \mathrm{a}$ is a plan view of the seamount grey shaded according to height. Figure $7 \mathrm{~b}$ shows an estimate of the regional using a $12 \mathrm{~km}$ wide median filter (grdfilter [Wessel \& Smith, 1998]), which is distorted by the seamount. A regional estimated by using the SWT technique to detect, isolate and remove the seamount by using a number of profiles across the area is shown in Figure 7c. As with directional median filtering the planar seafloor is recovered exactly. The location of the profiles does not affect the result, and Figures $3 \& 4$ illustrate 2 perpendicular profiles taken at right angles through the seamount.

For synthetic data such as this the process of maximizing the ratio of area to outline, $r$, is alone sufficient to produce the result shown. None of the geometrical restrictions on the outward expansion of the seamount's limits are necessary.

\subsection{Hawaii}

The Hawaiian chain contains some of the largest volcanic edifices in the oceans in close proximity to much smaller ones (Figure 8a). Furthermore, some edifices are large enough to warp neighbouring seafloor downwards and create 'flexural bulges' whilst the same seafloor is affected by a 'hot spot swell' of about $1 \mathrm{~km}$ in amplitude and $1000 \mathrm{~km}$ in width [e.g. Crough, 1978; Wessel, 1993]. A profile across this landscape is therefore a good test of whether a technique can distinguish seamounts from other features.

Figures $8 \mathrm{~b} \& \mathrm{c}$ contrast the results of the SWT method with regional bathymetries estimated using sliding filters (i.e. mean, median and mode). A width of $480 \mathrm{~km}$ is used, a width found to optimally separate the main island chain from the swell by the ORS technique [Wessel, 1998]. In Figure 8b the mean (solid line) is 'pulled up' or biased to too shallow depths by the Hawaiian volcanoes and, because height of seamounts is measured as that above the regional, underestimates the height of the central volcano. The median (dashed) and mode (dotted) are less affected by this bias but do not accurately underline, and therefore isolate, the smaller volcanoes either side. Some smaller seamounts fall entirely below the regional, and would therefore not be identified at all, where the flexural bulge is above the regional it would be incorrectly identified as a seamount. Where the regional passes beneath several smaller seamounts at once they would be grouped into an individual feature. In Figure 8c the regional produced by the SWT method to identify and underline seamounts does not have these shortcomings.

What, however, is the sensitivity of the SWT method to the values of the various user-defined constants incorporated in the method? 
The first constants are used in the few cases where identifiable features of different morphologies occupy the same location (e.g. a seamount on a flexural bulge). The constants select the desired feature (Section 4.2). Since the aim of this interpretation is to select seamounts, flexural bulges with large $C_{x, w}$ and marked A and B on Figure 9a have been suppressed in favour of the seamounts upon them. Values of 'coefficient ratio' $C r$ and 'steepness ratio' $S r$ of 4.0 and 3.0 respectively have been chosen to do this (black line). To test the sensitivity of the output to these user-defined constants one was fixed at its chosen value whilst the other was varied (Figure 9a). As $\mathrm{Cr}$ is reduced, seamounts on the bulges must have $C_{x, w}$ closer in size to that of the bulge to eliminate them. With $\mathrm{Cr}$ reduced below 2.0 the bulges are underlined (grey line) instead of the seamounts on them being underlined (black line), but further reductions had no further effect. Raising $\mathrm{Cr}$ above 3.0 had no effect on the interpretation. As $S r$ is reduced small seamounts less markedly steeper sided than larger features can eliminate them. With $S r \leq 3.0$ the bulges were suppressed (black line) with the interpretation the same for all these values. When raised above $3.2 \mathrm{Sr}$ no longer suppressed the bulges (grey line), but no further changes occur however much it is raised.

The second set of user defined constants (see Section 4.3) acts after the correct features (e.g. seamount not flexural bulge) has been selected. They work to produce a sensible interpretation of the limits of a seamount for a small minority of circumstances where the feature and its context combine so that maximizing $r$ alone is not adequate. As above, one constant was varied whilst the rest remained at their chosen values: $W f=0.25, H r=1.25, O p=0.25, G r=5$. Decreasing $W f$ reduces the distance within which a new limit that increases $r$ can be explored for at each step. Decreasing $W f$ can cause the expansion of limits to be stopped by neighbouring subsidiary features. Specifically, for $W f$ values below 0.04 a feature marked $C$ on Figure $9 \mathrm{~b}$ stopped the expansion and produced the lightest grey line. Increasing $W f$ above 0.36 allowed the expansion to leapfrog seamounts and arrive at a stable solution isolating units larger than individual seamounts (darker lines). The interpretation, however, was invariant with $0.05<W f<0.36$ and to achieve a good interpretation it is not necessary for the edge to move more than $10 \%$ to $30 \%$ of a seamount's width in a single step. So, within this sensible range, the SWT interpretation is invariant to $\mathrm{Wf}$. $\mathrm{Hr}$ was varied from $1.1-10.0$ (must be $>1.0$ by definition) with no effect on the interpretation of this profile. $\mathrm{Hr}$ only has a significant effect where seamounts border trenches. $O p$ and $\mathrm{Gr}$ are additional regulators to stop areas that are too flat being included in a seamount. Decreasing $O p$ reduces the portion at the edge of the seamount in which the gradient at the edge is calculated. Reducing $G r$ counts steeper gradients as 'too flat'. Values of $O p$ from 0.05 to 0.3 gave identical results; above 0.4 the edge has too much overlap with the middle effectively nullifying this restriction. All $G r$ values $>3.0$ (middle more than three times steeper than the edge) gave the same result. Thus, the interpretation was robust and stable within a wide range of values of $O p$ and $G r$.

To summarize, gradational changes in user-defined constants do not result in a continuum of changes in the interpretation, rather the interpretation jumps between stable states, but with a large range of constants all producing the result in Figure 8c. In selecting which features to isolate (Section 4.2) there is threshold behaviour when $\mathrm{Cr}$ and $\mathrm{Sr}$ are used to distinguish between one stable state where flexural bulges are suppressed and one in which they are not. Then, when finding the limits of these features (Section 4.3) a regional is produced that is substantially invariant to the values of the constants, i.e. objectivity is approached. Note that these values of constants described above work in widely varying scenarios such as cruise v3312.

\subsection{Cruise v3312}

In 1976 the research vessel Vema cruised from Japan, crossed the Japan, Izu Ogasawara, and Marianas Trenches, and passed through the Magellan seamount province before arriving in Guam. This variety of environments (Figure 10a) makes cruise v3312 a good case study [Smith, 1990; Hillier, 2005]. Figure 10a shows a manual interpretation (bold line) [Hillier, 2005] and Figure 10b 
the result of a $400 \mathrm{~km}$ median filter suggested to perform the best regional-residual separation by Smith [1990]. Figures 10c \& d show the interpretation generated using the SWT method. Data gaps spanning height differences of $>200 \mathrm{~m}$ were filled by linear interpolation.

The manual interpretation [Hillier, 2005] was done before the SWT method was created, but the SWT method still matches the manual interpretation significantly better than any sliding window technique with any width (Figure 11a). The r.m.s (root mean square) misfit between regional depths estimated by the SWT method and the manual interpretation is $144 \mathrm{~m}$ compared to $355 \mathrm{~m}$ for the best sliding window technique; by this measure a $125 \mathrm{~km}$ wide median. Much of the $144 \mathrm{~m}$ of error is due to two localities where a 'correct' interpretation is ambiguous that are circled on Figure 10a. Where seamounts unambiguously stand on relatively flat seafloor between 2800 and $5600 \mathrm{~km}$ along track the misfit due to the SWT method is $25 \mathrm{~m}$, five times less than the best median filter (r.m.s of $129 \mathrm{~m}$ ) which by this measure is $200 \mathrm{~km}$ wide (Figure 11b).

A notable difference occurs between how the methods isolate seamounts within trenches. Specifically, the SWT interpretation performs effectively when isolating seamounts of various sizes within the Marianas Trench (Figure 12b). $400 \mathrm{~km}$ and $50 \mathrm{~km}$ wide median filters are shown for comparison as they most clearly illustrate the two factors affecting the $125 \mathrm{~km}$ median (Figure 12a). The larger filter cannot descend the trench, but even the $50 \mathrm{~km}$ wide filter cannot reach the bottom of the trench (located ' $G$ ') and is too shallow inside larger seamounts (located ' $F$ '). Thus neither small nor large filters, or indeed a $125 \mathrm{~km}$ wide one, can both descend the trench and underline features within it.

Methods may also be compared to the manual interpretation in terms of the number and size of the features found. Here, features are recognised as any heights above an interpreted regional, and the height of features quantified as the maximum difference between observed and regional heights within each feautre. The manual interpretation finds 345 seamounts in cruise v3312, the SWT method 333, and a $200 \mathrm{~km}$ wide median filter 170. These, however, do not necessarily correspond to each other. For direct comparison, manually isolated seamounts are taken as a standard and matched to any computationally derived seamount whose summit within their footprint. Where multiple computationally isolated seamounts exist the closest in height to the manually isolated one is chosen. For matched seamounts SWT derived estimates of their height, $h$, correlate well $\left(r^{2}>\right.$ $0.9)$ with manual ones whether all seamounts $(h<5 \mathrm{~km})$ or only small ones $(h<0.4 \mathrm{~km})$ are considered (Figures $13 \mathrm{a}-\mathrm{c}$ ). With the $200 \mathrm{~km}$ median filter, however, correlations drop markedly for smaller seamounts (Figures $13 \mathrm{~d}$-f). If a further stipulation is added requiring seamounts to be within $\pm 25 \%$ of the manually estimated value in both height and width the SWT method matches 159 manually derived seamounts, whilst the median only matches 25.159 out of 345 is somewhat low, but most of the difference results from very small seamounts $(h<0.2 \mathrm{~km})$ with 19 of 24 matched for $h>1 \mathrm{~km}$. Figures $13 \mathrm{~g} \& \mathrm{~h}$ illustrate the extent to which the SWT and median filter respectively match manually derived estimates of $h$ as a function of $h$. Table 2 also tabulates illustrative results. Overall the SWT method matches the manually isolated seamounts much better than the best sliding window technique.

The sensitivity of the output of the SWT analysis to the user-defined constants is similar to that for the Hawaii profile. Varying constants $\mathrm{Cr}$ and $\mathrm{Sr}$ used to select seamounts in Section 4.2 causes jumps between stable visually acceptable states, but $C r=4.0$ and $S r=3.0$ are acceptable values. There is little sensitivity to $G r$ and $O p$, and sensible $W f$ values (i.e. $0.01<W f<1.0$ ) achieve the best results. $H r$, however, was included to regulate the undue expansion of seamounts directly abutting steep trenches, marked D \& E on Figure 10c. As $\mathrm{Hr}$ increases steeper and less geologically plausible baselines are permitted as illustrated on Figure 5c. In these 2 locations the interpretation changes continuously as $\mathrm{Hr}$ does, but at $\mathrm{Hr}=1.25$ the result appears geologically plausible. 


\subsection{Gridded Data}

Much commonly used bathymetry data is in the form of 'grids' i.e., data points in lattices of regularly spaced points [e.g. Smith \& Sandwell, 1997]. The utility of the SWT technique in analysing such a grid is tested in a region of $\sim 20,000 \mathrm{~km}^{2}$ around Hawaii (Figure 14a). Using the method of Hillier \& Watts [2004, 2005] the grid is sampled along sets of profiles in four orientations, namely every $45^{\circ}$ of azimuth as direction along profile is irrelevant. Separation between N-S and E-W profiles is $0.1^{\circ}$, and latitudinal separation between NE-SW and NW-SE profiles is $0.2^{\circ}$. For each set of profiles, regional bathymetries from individual profiles are gridded (blockean \& surface of GMT [Wessel \& Smith, 1998]). Then, at each grid point, the deepest of the four grids is selected for the final regional bathymetry (Figure 14b). The deepest points are selected as some profiles, such as directly along the Hawaiian chain, will be shallower than a geologically meaningful regional depth [Hillier \& Watts, 2004]. Residual bathymetries (Figure $14 c, d)$ are calculated by subtracting a regional bathymetry from the observed (Figure 14a).

The SWT technique isolates seamounts of all sizes into a residual bathymetry (Figure 14c). Topography associated with fracture zones is also isolated, and absence of these features in the regional bathymetry (Figure 14b) indicates that removal is complete. Most linear artefacts in the residual are present in the original bathymetry, however 4 prominent lineations occur that are orientated along tracks used in the SWT mesh (e.g. white arrow). Here, the SWT method has erroneously selected the flexural bulge. Notable errors, however, have only occurred on $<0.5 \%$ of the 844 profiles in the mesh, on the order of $0.01 \%$ for individual features. For clarity of display, contours on Figure 14b were computed after smoothing the regional with a $100 \mathrm{~km}$ median filter, however a residual computed from this smoothed bathymetry is free of the SWT artefacts whilst retaining resolution sufficient that the flexural trough and bulge are clear in the regional bathymetry (Figure 14b).

A contrast to the results of the SWT filter are those of a $480 \mathrm{~km}$ median filter considered to optimally separate the Hawaiian swell by Wessel [1998]. Firstly, around the Hawaiian chain, both edifices and flexural features are placed into the residual (Figure 14f). Red colours indicate where the regional bathymetry rises above the observed seafloor surrounding the edifices. The same red, however, occurs around the Musicians seamounts which were emplaced onto young seafloor and do not have prominent flexural features. Height of these seamounts in the residual will therefore be underestimated. Some detail in the shape of the swell may also have been lost (Figure 14e)

\section{Computational Speed}

The code for the SWT algorithm is written in C. With the parameters indicated in the paper and using a $1.33 \mathrm{GHz}$ ibook with $512 \mathrm{MB}$ RAM it takes 8.7 seconds to analyze 5680 depth data spread over $6949 \mathrm{~km}$ of cruise v3312. 333 features are found, 38.3 features per second. 750 data every 2 $\mathrm{km}$ across the Hawaiian Chain contains 38 features found in 0.8 seconds, 47.5 features per second. It is therefore practical to analyze significant amounts of data using the SWT method. For comparison, a $400 \mathrm{~km}$ wide median filter for the cruise v3312 using filter1d of GMT (Wessel \& Smith, 1998) takes 0.6 seconds. Analysis of the gridded data (Section 5.4) is considerably slower: the 844 profiles takes 22 minutes 43 seconds to analyze. For comparison, the $480 \mathrm{~km}$ median filter (grdfilter of GMT) takes 13 minutes 57 seconds.

\section{Discussion}


Accurate, objective and reproducible detection and isolation of seafloor features so that their shape may be assessed and, if desired, later sub-categorised has the potential to provide valuable constraints on solid Earth processes. For example, seafloor volcanoes reflect the generation and ascent of magma [e.g. Vogt, 1974; Smith \& Cann, 1992]. The dramatic variation in size and shape of seamounts [e.g. Jordan et al, 1983; Smith, 1996] that is the richness of this record, however, also presents problems for computational approaches to seamount isolation. Methods that deduce seamount dimensions as the difference from a larger-scale 'regional' bathymetry [e.g. Smith, 1990; Wessel, 1998; Ali, 2003; Kim \& Wessel, 2008] currently only do so by choosing a single filter width. Existing methods to directly isolate seamounts from bathymetry are scale invariant, finding points of equal height around a feature, then use more [Hillier \& Watts, 2004] or less [Behn et al, 2004] complex shape based criteria to accept or reject the feature as a seamount. Wavelets (Figure 2) offer a previously untried approach to this task where multiple scales are considered and the selected scale may vary across the area of analysis. Before discussing the ability of the SWT method to isolate seamounts, however, a question of terminology must be considered: Is the SWT a wavelet method?

\subsection{Is the SWT a Wavelet Method?}

Since the SWT method does not use a standard numerical method such as a discrete wavelet transform DWT, and the wavelet used (Figure 2) does not conform to some mathematical requirements usually placed on wavelets (e.g. the square of the wavelet function integrates to unity [Percival \& Walden, 2000]), is it appropriate to use the term wavelet?

The term wavelet is used because, in essence, a wavelet is a small wave, a function of non-zero amplitude over a finite period of a time series [Percival \& Walden, 2000]: the 'wavelet' used in the SWT method (Figure 2) is precisely this. Wavelet analysis 'tells us how weighted averages of certain other functions vary from one averaging period to the next' [Percival \& Walden, 2000]. The computation of wavelet coefficients in Section 4.2 is the computation of weighted averages (albeit means with weights of $+/-1$ ) between segments of bathymetry time series: i.e., exactly as wavelet analysis is described. Furthermore, the SWT method combines wavelet coefficients as a function of wavelet scale and wavelet location to generate a wavelet transform (WT) that is a 2D function which resembles DWTs. It therefore appears appropriate to use the term wavelet in conjunction with this analysis even if it must be stressed that the approach to compute the WT is an unusual one.

\subsection{Choice of Computational Method}

The computational method dubbed collectively the 'SWT method' consists of three independent stages (Section 4) within which the exact mode of computation has no bearing on the other stages. The 'SWT method' presented is therefore a framework, a flexible basis that may be tailored and optimized.

In the first stage a WT is computed. Any suitable wavelet could be used e.g. Mexican Hat. The wavelet in Figure 2 and computation in the space domain as the difference of three means (Section 4.1) were selected for several reasons. Firstly, SWT computation is not mathematically involved like traditional methods [e.g. Percival \& Walden, 2000]. It is therefore very simple to customize the wavelet; for instance, bathymetry on both sides was required to be shallower than the middle and either side was prevented from descending a deep trench. Such customizations significantly optimize WTs of bathymetry for the purposes of seamount detection i.e., create distinct signals clearly related to seamounts (Figure 5). Secondly, in a traditional discrete wavelet transform (DWT) coefficient spacing in the WT, and thus sensitivity of seamount location, decreases at larger scales. In the SWT method WT coefficients can be computed at any spacing at any scale, so 
sensitivity is maintained. A minor advantage of the SWT method is that the profile does not need to be re-sampled to $2^{\mathrm{n}}$ evenly spaced points. Lastly, the potential exists to use medians instead of means in order to make the SWT method more robust to data outliers. A number of the usual mathematically convenient properties of the WT are lost for the SWT as compared to DWT methods, but it is optimized for the purpose of finding seamounts.

In the second stage wavelet coefficients best fitting seamounts are selected. Many methods could be used here. Perhaps, areas of scale-amplitude space representing flexural bulges could simply be defined and excluded instead of the method chosen (Section 4.2).

The third stage presents a method to implement a powerful seamount isolation parameter adapted from the ORS separation of Wessel [1998]. Maximizing the parameter, a ratio of area to outline of a seamount on a profile, plausibly delimits the vast majority of seamounts. Other methods, perhaps rolling the edges downhill until the seafloor flattens too much or a larger seamount is encountered, could be substituted here.

Overall, despite the apparent complexity of the description in this paper, the method is no more complex than other solutions to object identification [e.g. Starck et al, 2000]. It is also sufficiently computationally efficient so as not to preclude analysis of large datasets. More generally, the SWT method could be adapted to isolating other topographic features e.g. drumlins [Hillier \& Smith, 2008]. It performs well when compared to alternative techniques.

\subsection{Performance of the SWT method}

Accurately isolating a conical seamount of arbitrary size on a sloping plane via an estimated regional bathymetry has only recently been achieved using directional median filtering (DiM) and ORS determination of filter width [Kim \& Wessel, 2008]: Figures $4 \& 7$ show that the SWT method performs equally well, exactly recovering the plane inside and outside the seamount. The SWT method, however, continues to perform similarly on real data across Hawaii where multiple sizes of seamount occupy the area (Figure 7c). Again, outside seamounts, measured seafloor is exactly reproduced in the filter's output. In contrast, the DiM filter across Cape Verde well approximates the swell and does a good job of isolating the main edifice, but is not sensitive to the dimensions of smaller seamounts. With different capabilities, the filters are complementary.

Figure 11 compares the ability of the SWT method and an array of sliding window filters to reproduce a manual interpretation [Hillier, 2005] of a bathymetry profile in the western Pacific (Figure 10). For the whole profile misfit for the SWT method is less than half of that for the best windowed technique, whilst for a central region of seamounts on an approximately flat seafloor the SWT method is $>5$ times better than the best windowed technique. Correlation between heights estimated from manual interpretation and the SWT method is greater than that between manual and median estimates (Figures 13 a-f), especially at small sizes. Furthermore Figures $13 \mathrm{~g} \& \mathrm{~h}$ show that the size-frequency distribution, an important metric of seamount populations [e.g. Jordan et al, 1983; Smith \& Jordan, 1987; Scheirer et al, 1996; Hillier \& Watts, 2007], resulting from the SWT method much more closely matches the manually derived one than does the distribution resulting from optimal windowed filtering. So, the SWT method is a development in accurate seamount detection and isolation, but how far does it go towards fulfilling the characteristics of an ideal methodology proposed in the introduction?

\subsection{SWT's Characterstics as a Seamount Isolation Filter}

Like all other computational techniques mentioned in this paper, the SWT method produces results that are exactly reproducible between studies. This is the first desired characteristic. Inside a 
seamount, like an appropriate regional bathymetry produced by a subjectively [e.g. Smith, 1990] or objectively [Wessel, 1998; Kim \& Wessel, 2008] selected windowed filter, the SWT method produces a geologically reasonable estimate of seafloor depth had the seamount not existed. Outside seamounts, in contrast to windowed filters, the SWT method exactly reproduces the observed depths. Furthermore, the SWT method reliably isolates seamounts in the presence of both hot-spot swells and trenches. So, criteria 1 to 4 are fulfilled.

For methods intended to isolate more than a single size of seamount, it is also desired that the method be equally effective for all sizes of seamount. Like MiMIC [Hillier \& Watts, 2004], and for a lesser size-range the closed contour method of Behn et al [2004], the SWT method is effective across a size range of features although scatter does increase somewhat with decreasing seamount size. At these scales the scatter could be due to increased error in either the manual interpretation or the filter. Unlike MiMIC or the contour method the SWT method explicitly handles and retains information on the size-based hierarchy of seafloor features so that the process of selecting seamounts is more transparent.

Perhaps the most important criterion, and hardest to fulfil, is no. 7 that of objectivity. In particular, it is desirable that a minimum of assumptions about shape (e.g. cone [White et al, 1982] or Gaussian [Wessel \& Lyons, 1997]) be a priori placed upon seamounts. The wavelet used in the SWT method only imposes the stipulation that a seamount should rise above its surroundings, possibly the most general definition of a seamount. $r$, the parameter maximized to define seamounts' limits places no specific restrictions on shape. User-defined constants $\mathrm{Hr}$ and $\mathrm{Gr}$ are only used in a minority of cases and respectively stipulate only that the regional slope is not to steep and that a seamount ends when its edges are substantially less steep than the middle. Thus, the SWT method begins to approach a minimum of a priori assumptions. The interpretation produced by the SWT method is broadly insensitive to the values of user-defined constants, and in this sense approaches objectivity. Using a WT also obviates the need for any a priori assumptions about the size or location of seamounts such as is needed in the ORS method [Wessel, 1998]. Furthermore, no minimum size/coefficient threshold [e.g. Starck, 2000] is used. A further, if minor, advantage of the SWT method is that data need not be re-sampled to an even spacing or $2^{\mathrm{n}}$ data as, for example, is needed of Fast-Fourier Transform [e.g. McKenzie, 1980] or DWT based approaches.

The main current disadvantage of the SWT method is that it works on profiles. Whilst single-beam ship track data are the only data to directly measure the seafloor with global coverage, incomplete sampling is a serious issue [e.g. Jordan et al, 1983; Hillier \& Watts, 2007] and it is desirable that seamount detection routines work on gridded data. This is especially true as the interpolations between ship tracks using satellite altimetry to create the commonly used bathymetry girds [e.g Smith \& Sandwell, 1997] improve in resolution and the coverage of swath bathymetry increases past a few percent. Like MiMIC [Hillier \& Watts, 2004], the SWT method can be successfully extended to gridded data using closely spaced profiles (Figure 14) but unlike MiMIC it is not difficult to imagine how to extend the method to operate intrinsically on surfaces. Specifically, wavelets that include directionality (i.e. a direction of elongation) exist for surfaces. The anisotropic Mexican hat wavelet has been implemented for multi-scale analysis of rock fabric (i.e. preferred orientations of a size distribution of crystals) [Gaillot et al, 2007]. Indeed, this 'NOAWC' method may be powerful tool in itself for extracting information about seamounts from bathymetry grids. In the SWT method another dimension is conceptually easy to add for $r$ and all the other geometric parameters used. Furthermore, there is nothing to stop a routine being created whereby edges of a complex plan-view shape are moved away from the centre of an object on a surface, perhaps segment by segment. Admittedly, these extensions may be non-trivial to implement. 
In summary, the SWT method fulfils many of the criteria required of a filter to isolate seamounts, and thus represents a step towards objective and robust quantification and classification of seamounts from which insights into solid Earth processes might be gained.

\section{Conclusions}

The following main conclusions about the use of wavelet based methods for seamount detection and isolation may be drawn

- SWT, a novel and efficient algorithm based on wavelets, can accurately and reproducibly detect and then isolate seamounts across a range of scales whilst imposing few shape-related criteria and requiring no a priori knowledge of the scale and location of the seamounts. Specifically, the SWT method exceeds sliding window techniques in its ability to isolate seamounts whatever their size and shape from a complex and variable multi-scale topography.

- The SWT method consists of 3 stages; computation of a wavelet transform, selection of coefficients best representing seamounts, and then accurately determining the limits of the seamounts from the bathymetry. Since no stage need be computed exactly as presented in this paper, the SWT method is a flexible framework with the potential to be used and adapted for seamount detection.

- Through simple customizations, wavelets computed in the space domain can optimized to detect seamount in a variety of surroundings. An SWT method is therefore more robust than traditional WT methods [e.g. Starck et al, 2000] for the first stage of the SWT method.

- A parameter, $r$, the ratio of a seamount's cross-sectional outline to its area is, when maximized by exploring possible alternative edges for the seamount, a powerful means to determine the correct boundaries of seamounts in stage 3 . In the vast majority of cases no further requirement is needed, but when refinements are needed output of the SWT method is broadly insensitive to the value of user-defined constants giving an approach to universal applicability and objectivity. $r$ is an adaptation of a parameter devised by Wessel [1998].

- Overall, the SWT method is no more complicated than methods devised for analogous problems e.g. object detection in a cloudless night sky [Starck et al, 2000]

\section{Supplementary Material}

In order to make the findings of this paper as accessible as possible, the following are provided as supplementary material:

- Source code for the SWT method. Written in ' $\mathrm{C}$ '.

- Example shell script to run code on the Hawaii profile to verify compilation

- Data, manual interpretation, and SWT interpretation for the v3312 profile used in this study.

\section{Acknowledgements}

I thank Katie Johnston and 2 anonymous reviewers for their comments on an early version of the manuscript, and Alistair Crosby for helping me further refine the manuscript. The constructive reviews of Frederik Tilmann and Seung-Sep Kim much improved this paper. I am funded by St Catharine's College Cambridge. 


\begin{tabular}{|l|l|}
\hline Parameter & Value \\
\hline $\max . \mathrm{Cr}$ & 4.0 \\
\hline $\min . \mathrm{Sr}$ & 3.0 \\
\hline $\mathrm{Wf}$ & 0.25 \\
\hline $\mathrm{Gr}$ & 5.0 \\
\hline $\mathrm{Op}$ & 0.25 \\
\hline $\mathrm{Hr}$ & 1.25 \\
\hline
\end{tabular}

Table 1: Preferred values of user-defined parameters.

\begin{tabular}{|l|l|l|l|l|l|l|}
\hline Height Range & \multicolumn{2}{|c|}{ SWT method } & \multicolumn{2}{c|}{ 200 km median } & \multicolumn{2}{c|}{125 km median } \\
\hline & $\%$ Matched & No. Matched & No. Matched & \% Matched & No. Matched & \% Matched \\
\hline$h<0.2 \mathrm{~km}$ & $41 \%$ & 119 of 287 & 7 of 287 & $2 \%$ & 8 of 287 & $3 \%$ \\
\hline$h>0.2 \mathrm{~km}$ & $69 \%$ & 40 of 58 & 18 of 58 & $31 \%$ & 15 of 58 & $26 \%$ \\
\hline$h>1.0 \mathrm{~km}$ & $79 \%$ & 19 of 24 & 10 of 24 & $42 \%$ & 12 of 24 & $50 \%$ \\
\hline
\end{tabular}

Table 2: Comparison of the effectiveness of the SWT method, $200 \mathrm{~km}$ median and $125 \mathrm{k}$ median in matching manually estimated seamount heights for the bathymetry of cruise v3312. Matched seamounts are within the footprint of the manual estimate and are within $\pm 25 \%$ of the manual estimate in both height and width. 


\section{References}

Abers, G. A., Parsons, B., Weissel, J. K., 1988. Seamount abundances and distributions in the southeast Pacific. Earth Planet. Sci. Lett. 87, 137-151.

Ali, M. Y., Watts, A. B., Hill, I., 2003. A seismic reflection profile of lithospheric flexure in the vicinity of the Cape Verde Islands. J. Geophys. Res. 108, art no. 2239.

Allain, V., Kerandel, J., Andrefouet, S., Magron F., Clark, M., Kirby, D. S., Muller-Karger, F. E., 2008. Enhanced seamount location database for the western and central Pacific Ocean: Screening and cross-checking of 20 existing datasets. Deep-Sea Res. doi:10.1016/j.dsr.2008.04.004

Batiza, R., 1982. Abundances, distribution and sizes of volcanoes in the Pacific Ocean and implications for the origin of non-hotspot volcanoes. Earth Planet. Sci. Lett. 60, 195-206.

Behn, M. D., Sinton, J. M., Detrick, R. S., 2004. Effect of the Galapagos hotspot on seafloor volcanism along the Galapagos Spreading Center $\left(90.9-97.6^{\circ} \mathrm{W}\right)$. Earth Planet. Sci. Lett., 217, 331347.

Cazenave, A., Dominh, K., All`egre, C. J., Marsh, J. G., 1986. Global relationship between oceanic geoid and topography. J. Geophys. Res. 91. 11439-11450.

Cheng, Y. Y., Yu, J., Zhong, J. Y., 2001. An adaptive filter for processing analytical signal based on fractal dimension. Chinese Journal of Analytical Chemistry 29 (11), 1246-1250.

Cserepes, L., Christensen, U. R., Ribe, N. M., 2000. Geoid height versus topography for a plume model of the Hawaiian Swell. Earth Planet. Sci. Lett. 178, 29-38.

Clouard, V., Bonneville, A., 2005. Ages of seamounts, islands, and plateaus on the Pacific plate. 7192. In 'Plates, Plumes and Paradigms', Geological Society of America Special Paper 388, Foulger, G. R., Natland, J. H., Presnall, D. C., Anderson, D. L. (Eds.).

Craig, C. H., Sandwell, D. T, 1988. Global distribution of seamounts from Seasat profiles. J. Geophys. Res. 93, 10408-10420.

Crough, T.S., 1978. Thermal origin of mid-plate hot-spot swells. Geophys. J. R. Astr. Soc., 55, 451469.

Epp, D., 1984. Implications of volcano and swell heights for thinning of the lithosphere by hot spots. J. Geophys. Res. 89 (B12), 9991-9996.

Gaillot, P., Darrozes, J., de Saint Blanquat, M., 1997. The normalised optimised anisotropic wavelet coefficient (NOAWC) method: An image processing tool for multi-scale analysis of rock fabric. Geophys. Res. Lett. 24, 1819-1822.

Gupta, V. K., Ramani, N., 1980. Some aspects of regional-residual separation of gravity anomalies in a Precambrian terrain. Geophysics, 9, 1412-1426.

Hillier, J. K., Watts, A. B., 2004. "Plate-Like" subsidence of the East Pacific rise - South Pacific superswell system. J. Geophys. Res. 109 (B10102), doi:10.1029/2004JB003041.

Hillier, J. K., 2005. The bathymetry of the Pacific ocean basin and its tectonic implications. Ph.D. 
thesis, University of Oxford.

Hillier, J. K., Watts, A. B., 2005. Relationship between depth and age in the North Pacific Ocean. $J$. Geophys. Res., 110, art. no. B02405, doi: 10.1029/2004JB003406.

Hillier, J. K., Watts, A. B., 2007. Global distribution of seamounts from ship-track bathymetry data. Geophys. Res. Lett, 34, art. no. L113304, doi:10.1029/2007GL029874.

Hillier, J. K., Smith, M., 2008. Regional-Residual Separation; Strengthening the signal and visualizing glacial lineaments. Earth Surface Processes and Landforms, doi:10.1002/esp.1659

Hillier, J. K., 2007. Pacific seamount volcanism in space and time. Geophys. J. Int., 168, 877-889, doi:10.1016/j.jas.2006.09.011.

Jordan, T. H., Menard, H. W., Smith, D. K., 1983. Density and size distribution of seamounts in the eastern Pacific inferred from wide-beam sounding data. J. Geophys. Res. 88, 10508-10518.

Kim, S., Wessel, P., 2008. Directional median filtering for regional-residual separation of bathymetry. G3, 9, art. no. Q03005, doi:10.1029/2007GC001850.

Koppers, A. A. P., Staudigel, H., Pringle, A. S., Wijbrans, J. R., 2003. Short-lived and discontinuous intraplate volcanism in the South Pacific; hot spots or extensional volcanism? G3, 4, art. no. 1089.

Lazarewicz, A. R., Schwank, D. C., 1982. Detection of seamounts using altimetry. Geophys. Res. Lett., 9, 385-388.

Levitt, D. A., Sandwell, D. T., 1996. Modal depth anomalies from multibeam bathymetry: Is there a South Pacific Superswell? Earth Planet. Sci. Lett. 139, 1-16.

Lin, R. S., Hsueh, Y. C., 2000. Multichannel filtering by gradient information. Signal Processing 80, 279-293.

Marova, N. A., 2000. Seamounts of the world ocean: Features of their distribution by height and space. Marine Geology 42 (3), 429-422.

McKenzie, D. P., Watts, A. B., Parsons, B., Roufosse, M., 1980. Planform of mantle convection beneath the Pacific Ocean. Nature 288, 442-446.

McNutt, M. K., Fischer, K. M., 1987. The South Pacific Superswell. In: Keating, B. H., Fryer, P., R.Batiza, Boehlert, G. W. (Eds.), Seamounts, Islands and Atolls Geophys. Mono. 43. American Geophysical Union, Washington D.C, pp. 25-34.

McNutt, M., Sichoix, L., 1996. Modal depths from shipboard bathymetry: There IS a South Pacific Superswell. Geophys. Res. Lett. 23, 3397-4000.

Menard, H. W., 1959. Geology of the Pacific seafloor. Experimentia, 15(6), 205-244.

Minshull, T. A., Charvis, P., 2001. Ocean island densities and models of lithospheric flexure. Geophys. J. Int., 145, 731-739.

Mofjeld, H. O., Titov, V. V., Gonzalez, F. I., Newman, J. C., 2001. Tsunami scattering provinces in the Pacific Ocean. Geophys. Res. Lett., 28, 335-337. 
Mofjeld, H. O., Symons, C. M., Lonsdale, P., Gonzalez, F. I., Titov, V. V., 2004. Tsunami scattering and earthquake faults in the deep Pacific Ocean. Oceanography, 17, 38-46.

Percival, D. B., Walden, A. T., 2000. Wavelet Methods for Time Series Analysis. Cambridge University Press.

Sandwell, D. T., Renkin, M., 1988. Compensation of swells and plateaus in the North Pacific: No direct evidence for mantle convection. J. Geophys. Res. 93, 2775-2783.

Scheirer, D. S., Macdonald, K. C., 1995. Near-axis seamounts on the flanks of the East Pacific Rise, $8^{\circ} \mathrm{N}$ to $17^{\circ} \mathrm{N}$. J. Geophys. Res., 100, 2239-2259.

Scheirer, D. S., MacDonald, K. C., Forsyth, D. W., 1996. Abundant seamounts of the rano rahi seamount field near the southern east pacific rise, 15 degreess to 19 degrees S. Marine Geophysical Researches 18, 13-52.

Sichoix, L., Bonneville, A., McNutt, M. K., 1998. The seafloor swells and superswell in French Polynesia. J. Geophys. Res. 103, 27123-27133.

Smith, D. K., Cann, J., 1992. The role of seamount volcanism in crustal construction at the MidAtlantic Ridge (24-30N). J. Geophys. Res., 97, 1645-1658.

Smith, D. K., Jordan, T. H., 1988. Seamount statistics in the Pacific Ocean. J. Geophys. Res. 93, 2899-2918.

Smith, D. K., 1988. Shape analysis of Pacific seamounts. Earth Planet. Sci. Lett. 90, 457-466.

Smith, D. K., 1996. Comparison of the shapes and sizes of seafloor volcanoes on Earth and 'pancake' domes on Venus. Journal of Volcanology and Geothermal Research 73, 47-64.

Smith, W. H. F., 1990. Marine geophysical studies of seamounts in the Pacific Ocean basin. Ph.D. thesis, Columbia Univ., 216 pp.

Smith, W.H. F., Sandwell, D. Global seafloor topography from satellite altimetry and ship depth soundings. Science, 277, 1956-1962

Starck, J. L., Bijaoui, A., 1994. Filtering and deconvolution by the wavelet transfrom. Signal Processing 35, 195-211.

Starck, J. L., Bijaoui, A., Valtchanov, I., Murtagh, F., 2000. A combined approach for object detection and deconvolution. Astronomy \& Astrophysics Supplemental Series 147, 139-149.

Vogt, P. R., 1974. Volcano height and plate thickness. Earth Planet. Sci. Lett. 23, 337-348.

Watts, A. B., 1976. Gravity and bathymetry in the central Pacific ocean. J. Geophys. Res., 81 15331548.

Watts, A. B., Daly, S. F., 1981. Long wavelength gravity and topography anomalies. Ann. Rev. Earth Planet. Sci. 9, 415-448. 
Watts, A. B., McKenzie, D. P., Parsons, B. E., Roufosse, M., 1985. The relationship between gravity and bathymetry in the Pacific Ocean. Geophys. J. R. Astr. Soc., 83, 263-298.

Wessel, P., 1993. Observational constraints on models of the Hawaiian hot spot swell. J. Geophys. Res., 98, 16095-16104.

Wessel, P., Lyons, S., 1997. Distribution of large Pacific seamounts from Geosat/ERS-1: implications for the history of intraplate volcanism. J. Geophys. Res., 102, 22459-22475.

Wessel, P., Smith, W. H. F., 1998. New, improved version of Generic Mapping Tools released. Eos Transactions of the American Geophysical Union 79, 579.

Wessel, P., 1998. An empirical method for optimal robust regional-residual separation of geophysical data. Mathematical Geology 30, 391-408.

Wessel, P., 2001. Global distribution of seamounts inferred from gridded Geosat/ERS-1 altimetry. $J$. Geophys. Res. 106, 19431-19441.

White, J. V., Sailor, R. V., Lazarewicz, LeShack, A. R., 1983. Detection of seamount signatures in SEASAT altimeter data using matched filters. J. Geophys. Res., 88, 1541-1551.

Yatawara, N., Abraham, B., MacGregor, J. F., 1991. A Kalman filter in the presence of outliers. Communications in Statistics - Theory and Methods 20, 1803-1820. 


\section{Figure Captions}

Figure 1: a) The Haar wavelet for a time-series; developed by A. Haar in 1910 and arguably the oldest wavelet [Percival \& Walden, 2000]. b) Normalised Mexican hat wavelet.

Figure 2: Wavelet used in the SWT method of seamount isolation a) Weightings that constitute the wavelet b) Schematic illustration of what the wavelet coefficient $C_{x, w}$ in effect calculates i.e., the average height difference between the heights in the centre of the wavelet and those surrounding the centre. In the illustrated case, a wavelet approximating the width-scale of the seamount (grey shaded) and centred on it is shown. Topography of the seamount is schematic and for illustration only, so heights are exactly zero outside the seamount. Average height within the central section is $z_{c}$, whilst and outside sections are $z_{l}$ and $z_{r}$, and all are shown as bold horizontal lines.

Figure 3: Wavelet transform of a simple synthetic seamount. Following Kim \& Wessel [2008] the seamount is conical with a radius of $3 \mathrm{~km}$ and summit height of $3 \mathrm{~km}$ above the flat surrounding seafloor. a) Bathymetry profile (thin line) across the summit of a conical seamount (grey shades) on a flat-lying seafloor. Depths are every $0.1 \mathrm{~km}$. White circle outlined in black locates the highest amplitude best-fitting coefficient from b): the associated bold horizontal bar indicates the span of the central part of this wavelet $\pm w / 4$. Thick black line is the regional bathymetry (i.e. pre-existing seafloor before seamount was added) as estimated by the SWT method (see text for details). b) WT of the profile. Coefficients $C_{x, w}$ at each scale $w$ with their centres $x_{i}$ at distances along the profile are grey-shaded with large coefficients light coloured, whilst dark shades are small coefficients. For display raw coefficients are gridded using surface [Wessel \& Smith, 1998]. White circle outlined in black is the highest amplitude best-fitting coefficient.

Figure 4: Wavelet transform of 2 synthetic seamounts, one small and one large, on a sloping regional bathymetry. a) Bathymetry as Figure 3 b) WT as Figure 3, expect greyscale get lighter for smaller coefficients to highlight coefficients of the smaller seamount.

Figure 5: Bathymetry across the Marianas Trench collected by the v3312 (bottom) and associated WT (top) for a series of space-domain refinements to the computation of wavelet coefficients implemented from left (a) to right (c). Bathymetry is the thin line, regional bathymetry derived by drawing under the isolated seamounts is the bold line (Section 4.3) and seamounts are shaded grey. In terms of distance along the ship-track the WT is aligned with the bathymetry. High amplitude WT coefficients are white whilst black is zero amplitude. Circles locate coefficients that best represent the scale and location of seamounts. a) WT with no refinements. b) Refinement 1 applied (see text). c) Refinement 2 applied (see text). The triangle is the coefficient best representing the bulge neighbouring the trench to its left, which is suppressed because it is not a seamount and does not influence the determined regional bathymetry. In the circumstance, $\mathrm{D}, \mathrm{Hr}$ of 1.25 prevents the baseline descending as indicated by the arrow (see text Section 5.3).

Figure 6: Schematic section of a bathymetric profile to illustrate the parameters used during the computation described in Section 4.3. The irregular line is bathymetry, thin outside the current best estimate of seamount width (i.e. between left and right limits - black dots) and thick inside these. Area of seamount $A$ is shaded grey and the outline $o$ is bold. Arrows indicate the two limits moving outwards from the summit. Note that the summit and limits become different from $x_{i} \pm w / 4$ at this stage of the computation.

Figure 7: Comparison of spatial median filter, directional median filter, and the SWT method on the synthetic data composed of a cone on a sloping plane. a) Original synthetic data b) Result of using the median filter (width $12 \mathrm{~km}$ ) to estimate a regional height surface c) Result of using the SWT technique to remove the seamount. 
Figure 8: Comparison of windowed filters and the SWT method on a bathymetric profile across the Hawaiian Chain. a) Location map showing bathymetry and the profile. Profile between $197.9^{\circ} \mathrm{E}$, $15.9^{\circ} \mathrm{N}$ and $210.0^{\circ} \mathrm{E}, 27.0^{\circ} \mathrm{N}$ is re-sampled at $2 \mathrm{~km}$ spacing from a grid of $1^{\prime} \mathrm{x} 1^{\prime}$ grid created using NGDC ship-track data (i.e. blockmode, then surface -T0.35 of GMT [Wessel \& Smith, 1998]); 0 to $1500 \mathrm{~km}$ shown. b) Bathymetry profile (thin line) and regional bathymetries estimated by $480 \mathrm{~km}$ wide mean (thick line), median (dashed line) and model (dotted line) filters. c) Regional bathymetry estimated by the SWT method (bold line) by extrapolating under detected seamounts (grey). d) WT of the bathymetry profile. Circles are the coefficients best fitting the seamounts.

Figure 9: Analysis of sensitivity of the SWT interpretation to user-defined constants for a profile across the Hawaiian Chain (see text). a) Constants used in Section 4.2 to select seamounts over flexural bulges, marked A \& B. 2 solutions exist if $\mathrm{Cr}$ and $\mathrm{Sr}$ are varied, one underlining seamounts (black line) and one underlining bulges (grey line, $\mathrm{Cr}<2.0$ or $\mathrm{Sr}>3.2$ ). b) Constants used in Section 4.3 to isolate selected seamounts. Within wide ranges of constants output is constant. Largest effect is produced by varying $W f$. $W f \leq 0.04$ (lightest grey line) illustrates why $W f$ is necessary i.e. expansion snags on subsidiary feature marked C. The black line is the preferred interpretation as in Figure 8c, $0.05<W f<0.36$. Solid grey is for $0.37 \leq W f<0.84$. Dashed grey is for $W f \geq 0.85$ to at least 1.0 , which being a movement of the whole width of the seamount in one iteration is much greater than would ever be appropriate.

Figure 10: SWT method applied to v3312. Single beam echo soundings were taken on average every $1.62 \mathrm{~km}$. a) Bathymetry (thin line) and manual interpretation [Hillier, 2005] (bold). Areas of ambiguous interpretation are circled. Vertical grey lines are limits of 2800-5600 km along track. b) Regional estimated by $400 \mathrm{~km}$ wide median filter (bold). c) Interpretation using the SWT method (bold) from d) the WT of the bathymetry.

Figure 11: Fit on the methods to a manual interpretation [Hillier, 2005] in Figure 10a. a) Root mean square (r.m.s) depth difference for the whole track. Filters computed using filter1d of GMT [Wessel \& Smith, 1998]. Scales are the width of the sliding window used, except for the SWT method where this indicates the maximum wavelet size. b) as for a) but for $2800-5600 \mathrm{~km}$ along track only.

Figure 12: Comparison between methods of the isolation of seamounts down the Marianas Trench. Data are from cruise v3312. a) Regional estimated using 50 (bold dashed line) and $400 \mathrm{~km}$ (bold line) median filters b) Result of the SWT method. Seamounts are grey shades.

Figure 13: Degree to which computationally derived estimates of seamount heights agree with manually derived estimates as a function of scale (i.e. height). a) - c) Scatter plots of manual vs. SWT derived seamount heights. Note the changing scale on the $x$ and y axes. d) $-\mathrm{f}$ ) Scatter plots of manual seamount heights vs those derived from a $200 \mathrm{~km}$ median filter. For the median seamounts are areas where measured depths are shallower than the regional depth approximated by the median filter. g) Histogram of number of manually derived seamounts (white) as a function of seamount height. Smaller grey bars are the number of SWT derived size estimates that match the manual ones. 'Matched' is defined as being in the footprint of the manually derived estimate and having a height and width within $\pm 25 \%$ of that of the manually derived estimate. $h$ ) is as $g$ ), but for the $200 \mathrm{~km}$ median filter. In g) and h) only heights $<1 \mathrm{~km}$ are shown as there are too few $>1 \mathrm{~km}$ to plot with any meaningful pattern on a histogram.

Figure 14: SWT method and a $480 \mathrm{~km}$ wide median filter applied to gridded data in the region around Hawaii. a) Relief-shaded bathymetry [Smith \& Sandwell, 1997]. FZ, fracture zone; s.t, ship 
track artefact; alt., altimeter noise; $\mathrm{B}$ and $\mathrm{T}$, flexural bulge and trench; H, Hawaii; M, Musicians Seamounts. White arrows point to exact locations. Insets bottom-right show the direction and spacing of the mesh of profiles used. b) Regional bathymetry calculated using the SWT technique. An unsmoothed regional is colour shaded whilst, for clarity, contours are after this has been smoothed with a $100 \mathrm{~km}$ wide median filter. c) and d) Residual bathymetries derived from the unsmoothed and smoothed SWT regional bathymetries respectively. e) and f) Regional and residual bathymetries calculated using an optimal [Wessel, 1998] $480 \mathrm{~km}$ wide median filter (grdfilter of GMT). Annotated contours are $0.5 \mathrm{~km}$ depth intervals. 

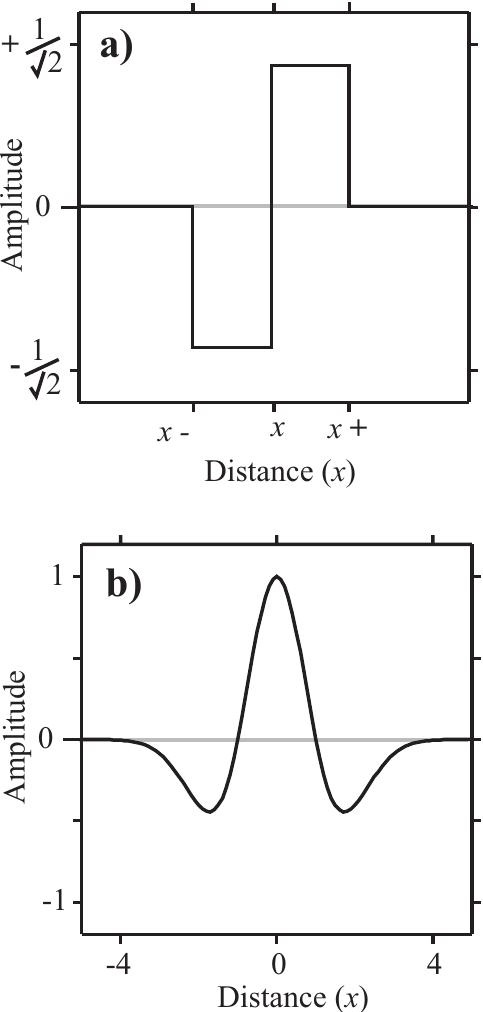
Weighting $\left(W_{i}\right)$

a) +1

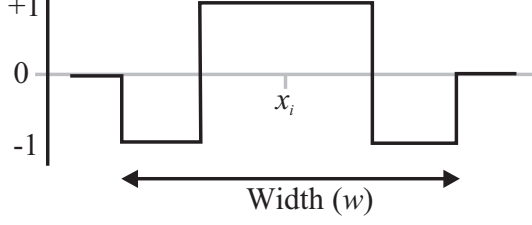

Distance (x)

b)

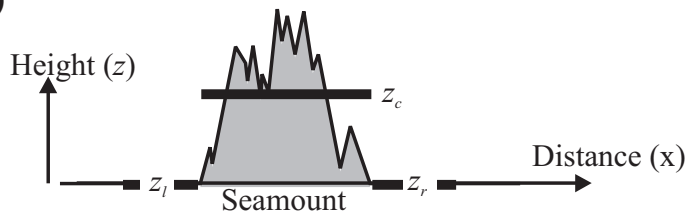




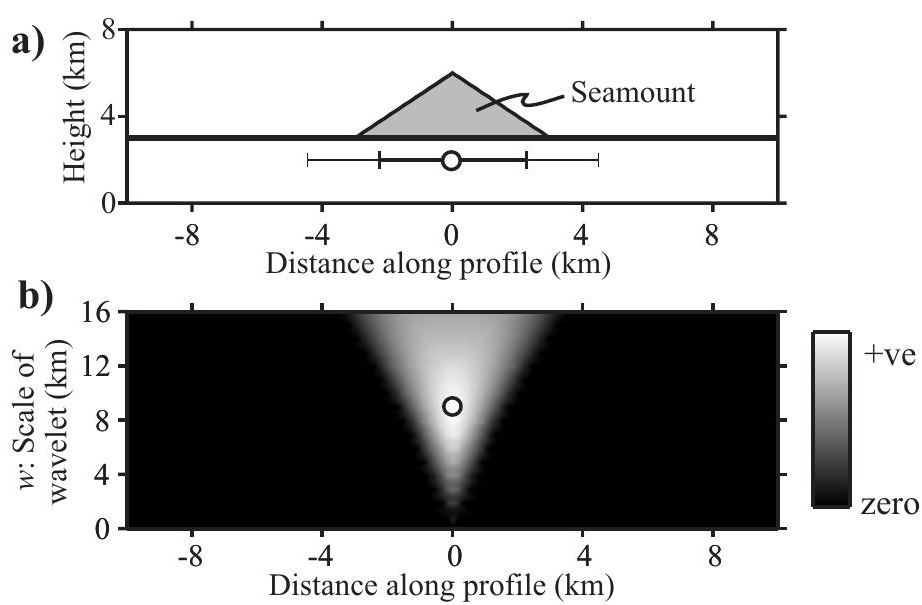




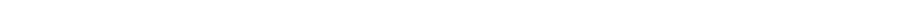


a) 300

ל

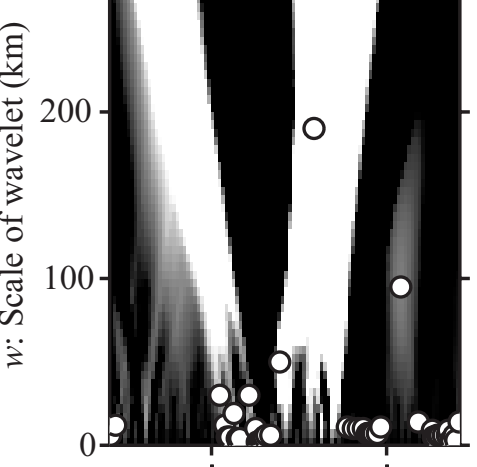

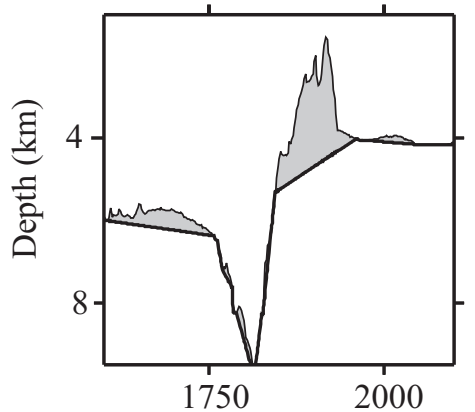
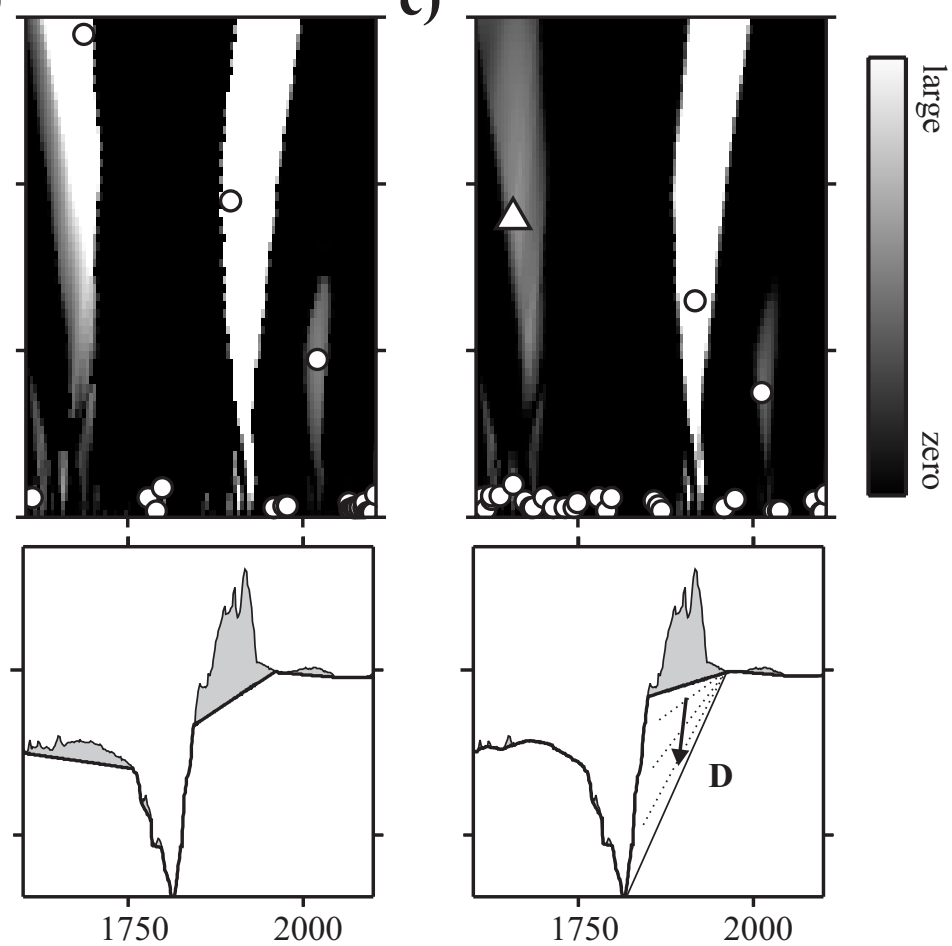

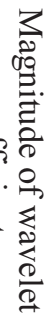

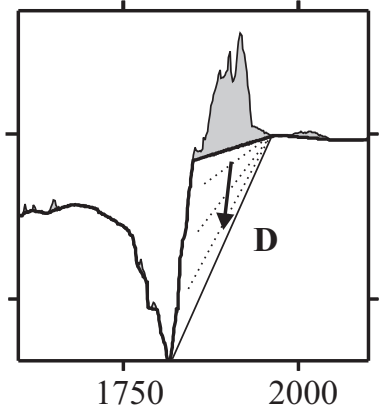

Distance along track v3312 (km) 


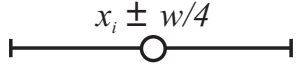

height (z)

summit $\left(x_{s}, z_{s}\right)$

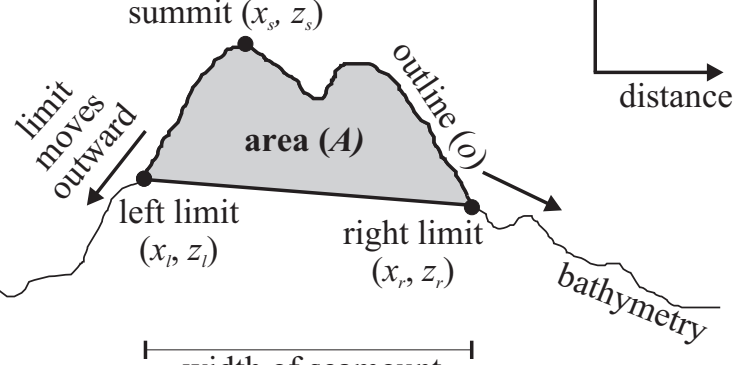

width of seamount 


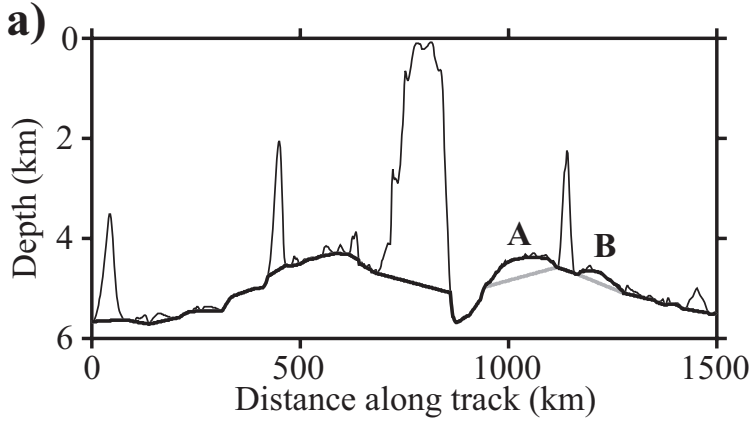

b)

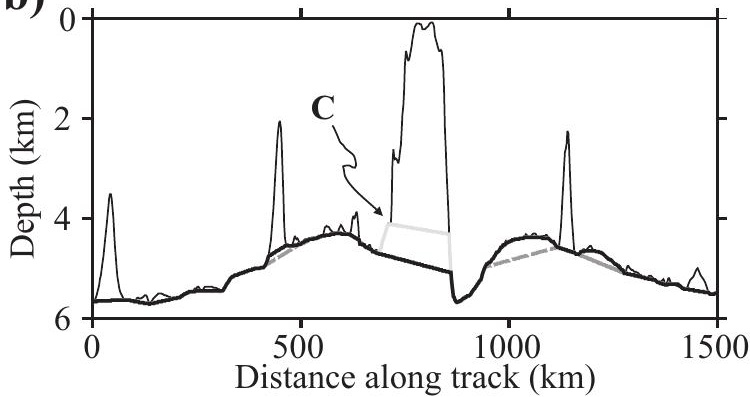


a)

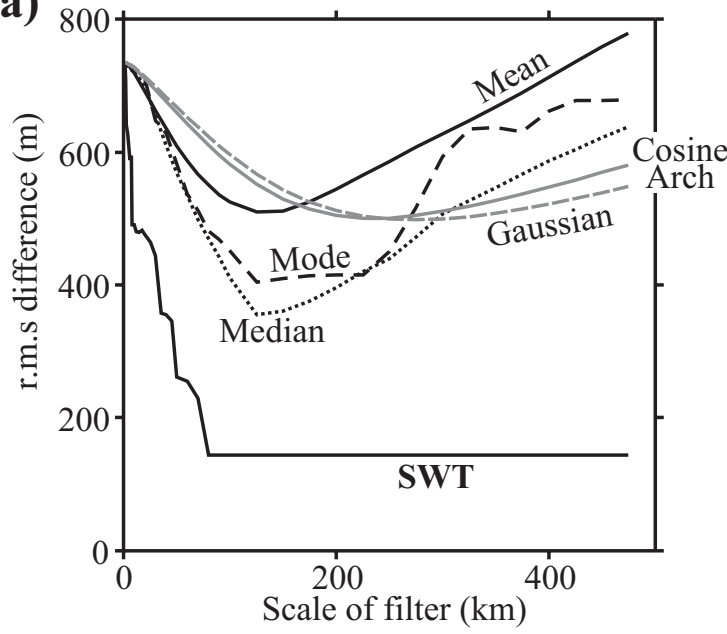

b)

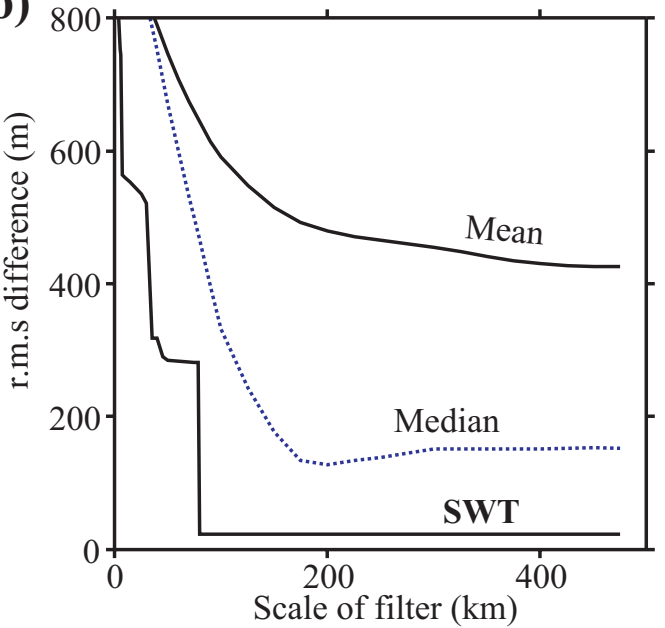



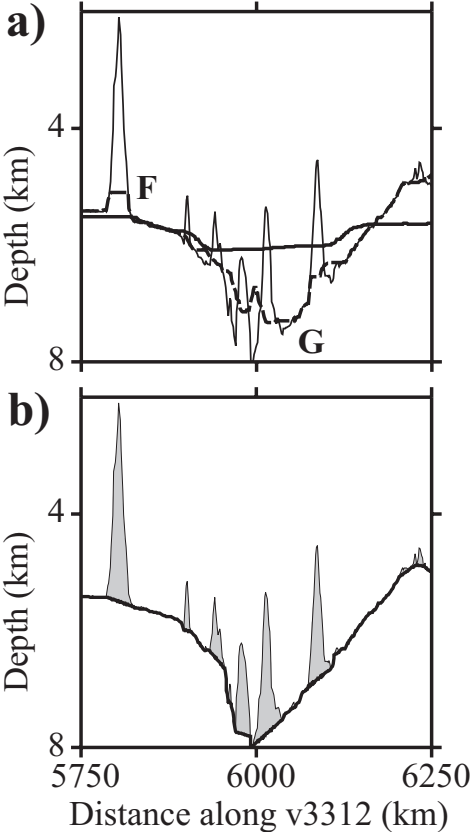

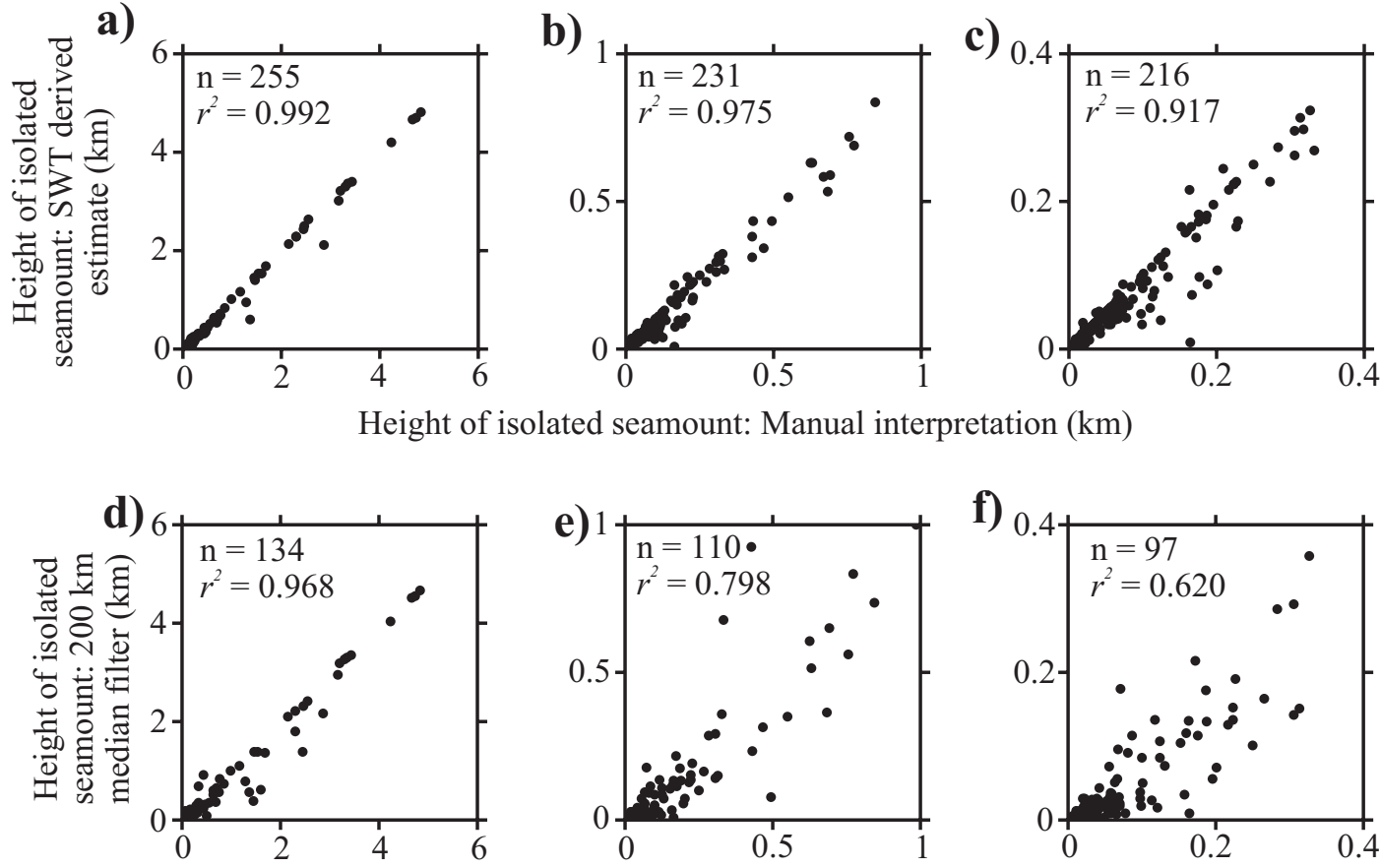

Height of isolated seamount: Manual interpretation $(\mathrm{km})$
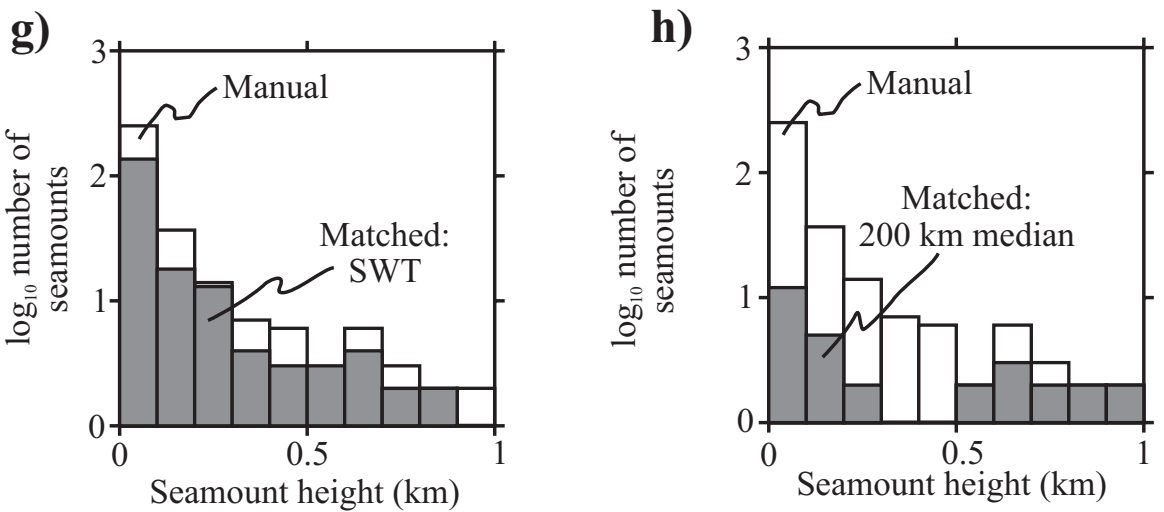

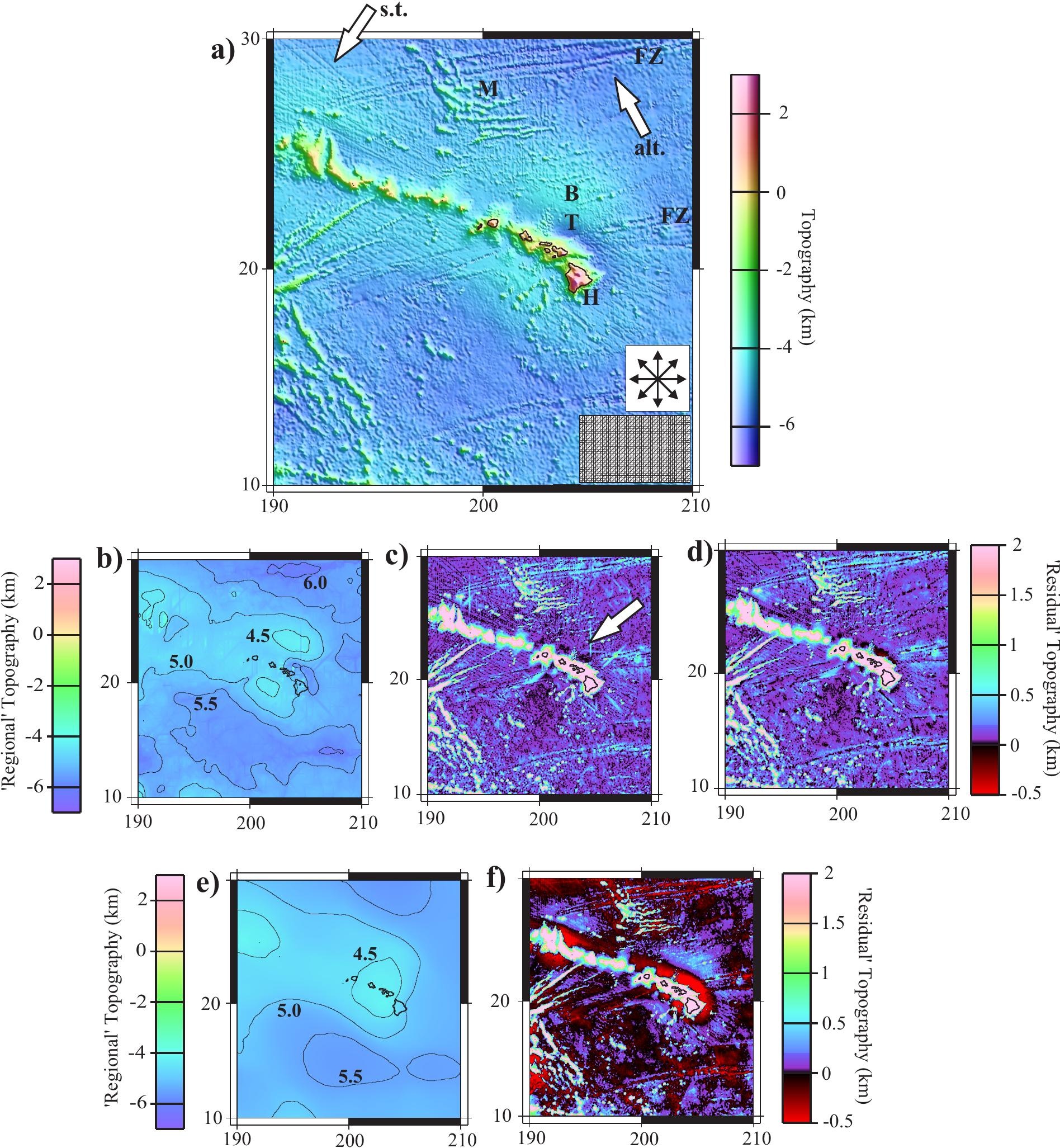